\title{
$R$ versus D: Estimating the differentiated effect of research and development on innovation results ${ }^{*}$
}

\author{
Andrés Barge-Gil ${ }^{\mathrm{a}}$ and Alberto López ${ }^{\mathrm{b}}$ \\ Universidad Complutense de Madrid
}

March 2011

\begin{abstract}
$R \& D$ is considered to be the main source of innovation. We argue that $R \& D$ is too broad a measure, including activities differing in purposes, culture, people, management and other features. However, empirical studies have not analyzed them separately, mainly due to the lack of data. Using firm-level data, the aim of this paper is to estimate the differentiated effect of research and development on different innovation outputs. Results show that both research and development activities are important. However, we find that development activities are more important for product innovation, while the effect of research activities is higher on process innovation. Moreover, we analyze differences by technological intensity of the sector. When analyzing product and process innovations, we find evidence supporting the existence of higher payoffs to development and, especially to research in low-tech sectors when compared with high-tech ones.
\end{abstract}

Keywords: R\&D, patents, product innovation, process innovation, impact.

\footnotetext{
${ }^{*}$ We would like to thank Elena Huergo for her valuable suggestions and discussion. We also wish to acknowledge the useful comments made by the audiences at the MICRO-DYN Summer School 2010 (Cambridge) and at seminars at the Manchester Institute of Innovation Research and at the Universitat de les Illes Balears. We acknowledge support from Fundación Ramón Areces. Errors are ours.

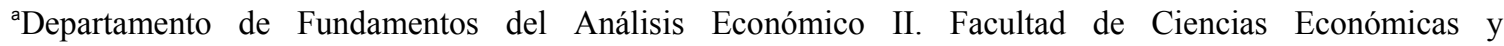
Empresariales. Universidad Complutense de Madrid.E-mail: abarge@ccee.ucm.es.

${ }^{\mathrm{b}}$ Departamento de Fundamentos del Análisis Económico I. Facultad de Ciencias Económicas y Empresariales. Universidad Complutense de Madrid.E-mail: alberto.lopez@ccee.ucm.es.
} 


\section{Introduction}

Research and development (R\&D) expenditures have long been an important concern for economists. Policy initiatives towards fostering R\&D have proliferated all around the world and at different levels of governance (local, regional, national and supranational). As a consequence, one of the main objectives of economists is to evaluate whether the returns to this investment justify the expenditure, and offer a guide to managers and policy makers on how to choose their investments and evaluate the success of different strategies (Wieser, 2005; Hall et al, 2010).

The most employed model is the "R\&D stock capital model", first introduced by Griliches (1979) to explore the relationship between R\&D and productivity. Following this model, a huge stream of literature has been developed. The abundance of this literature can be seen in the large number of surveys that have already been carried out on this topic: Griliches (1995), Hall (1996), Mairesse and Sassenou (1991); Mairesse and Mohnen (1995), Nadiri (1993) and, more recently, Wieser (2005) and Hall et al. (2010).

This model has been extended to estimate the effect of $R \& D$ on different innovation outputs, such as patents and number of innovations (and, more recently, sales due to innovations) (see, for example, Jaffe, 1989; Acs et al., 1992; Mairesse and Mohnen, 2005) ${ }^{1}$. These analyses employ the so-called "knowledge production function", again first introduced by Griliches (1979).

Literature on the economics of innovation considers R\&D the main source of innovation ${ }^{2}$. However, while most literature has considered R\&D to be a single and homogenous activity, research and development actually includes a myriad of heterogeneous activities (Mansfield, 1981; and Link, 1982). These activities differ in purposes, main features, culture, people involved and style of management, as is shown by case studies and the opinion of R\&D managers (see Chiesa and Frattini, 2007). In fact, research and development are usually performed by different departments of the firm which are under

\footnotetext{
${ }^{1} \mathrm{~A}$ further step in this literature is the paper by Crepon et al (1998). These authors propose a structural model (CDM model) for analyzing the relationship between $R \& D$, innovation and productivity.

${ }^{2}$ Although some authors (see, for example, Barge-Gil et al., 2011) have pointed out the importance of non-R\&D activities in innovation.
} 
the responsibility of different managers. Moreover, this kind of organization seems to be a major trend in future R\&D strategy (Chiesa 2001).

Assuming that R\&D includes two different activities, the aim of this paper is to explore the differences between "R" and " $D$ ", and analyze how they differently impact the innovation results of the firm. In doing this, we use a new firm-level data base for innovative activities (the Technological Innovation Panel, PITEC).

The results of this paper might be useful for academics, for policy makers and for R\&D managers. Firstly, this paper allows us to go further in our understanding of the innovation process. As pointed out by Mansfield (1981), R\&D expenditure is very heterogeneous and its composition may be as important as its total amount. In addition, the OECD classification of industries is based on R\&D intensity and, although it does not say anything about the relative weights of $\mathrm{R}$ and $\mathrm{D}$ in each industry, it is usually believed that high-tech industries are more science-based, while low-tech industries are usually more focused on engineering and development.

Second, this analysis is useful for policy makers. An increasing amount of public funds is destined to stimulating R\&D activities on different levels (local, regional, national and supranational). More precise knowledge about which component of $R \& D$ has a greater effect on different innovation outputs will be useful in designing more specific innovation policies.

Finally, the analysis is also of interest for R\&D managers who make decisions about the allocation of resources to different activities pursuing some specific results.

The rest of the paper is organized as follows. Section 2 focuses on the differences between research and development activities. Section 3 deals with the related literature. Section 4 describes the data used and presents a brief descriptive analysis of research and development for Spanish manufacturing firms. Section 5 sets out the empirical methodology, describing the econometric details, estimation method applied and the sample of firms and variables used in estimation. Section 6 presents the results. Finally, Section 7 concludes. 


\section{Differences between research and development}

R\&D includes basic research, applied research and development. However, we use only the split between research and development activities. Firstly, basic and applied research share many characteristics which distinguish them from development. Second, case studies show that the difference between basic and applied research is too diffuse (see, for example, Arnold, 2004; and van Ark et al., 2007). Therefore, some authors recommend collapsing basic and applied research in empirical studies (Balconi et al., 2010). Moreover, basic research represents a small share of total $R \& D$ expenditures. For example, in our sample of Spanish firms, basic research is around $3 \%$ of total R\&D expenditures.

In what follows, we are going to briefly expose the differences between research and development. We analyze these differences focusing on their purposes, their main features, the underlying culture, the style of management and the people involved in each activity. These differences are summarized in Table 1.

\section{Purposes}

The main purpose of both basic and applied research is to acquire new knowledge, while the main purpose of development is directed to the introduction of new or improved products or processes (OECD, 2005). In this sense, research is more theoretical in nature (although usually oriented to some practical objective) and their outputs are more related to the expansion of the knowledge base. On the other hand, development is essentially applied and usually attains physical outputs (Leifer and Triscari, 1987; Karlsson et al., 2004).

\section{Type of knowledge}

Some authors have argued that knowledge bases can differ between activities (Laestadius, 1998; Asheim and Coenen, 2005; Moodyson et al., 2008). We can distinguish between two knowledge bases: analytical and synthetical. An analytical knowledge base is closely related to research and leads to innovation by the creation of new knowledge. It is associated with scientific techniques involving mathematical and science-based theories and with tools and methods such as experimentation. Codified knowledge dominates due to documentation in patents and publications. Synthetic knowledge, for its part, is closely related to development and leads to innovation by application or novel combination of existing knowledge (Laestadius, 1998; Asheim and Coenen, 2005). It is more engineering- 
based, also involving the utilization of mathematics and other scientific formulae, but with a great emphasis on piecing together separate components into working systems, while satisfying many real-world constraints (Amsdem and Tschang, 2003). Tacit knowledge dominates due to more concrete know-how, craft and practical skill.

\section{People}

Research is more labour-intensive, while development is more material-intensive (Van Ark et al., 2007). People involved in research are generally more qualified and more specialized. The human factor is crucial for research and the importance of individuality is central to its effectiveness (Chiesa, 2001). However, development needs generalists (Karlsson et al., 2004). People involved in development activities are required to have a broader perspective, covering science, engineering and the market, and be able to manage across different corporate functions. Moreover, while in research the most creative people should not become managers, in development people should have an entrepreneurial spirit and combine a long-term strategic view with day-to-day activities (Chiesa and Frattini, 2007).

\section{Style of management}

Research units work relatively independently of the rest of the organization (Leifer and Triscari, 1987), they maintain close links with universities and research centers (Van Ark et al., 2007) and are much more based on individuals, the department being a very important dimension of analysis and management. In contrast, development activities often require coordination with other functional units of the organization, and even its approval. They establish close links with production and marketing departments and, ideally, also with actual or potential customers (Leifer and Triscari, 1987). In addition, they build much upon team work, usually interdepartmental (Chiesa and Frattini, 2007).

The management of research is characterized by less hierarchy. The specific features of research departments make them achieve coordination and control by a combination of leadership and a strong culture, due to the difficulty of ascertaining clear performance standards as well as the possibility of conflict between the values of the profession (for inventiveness and creativity) and values of the organizations (meeting deadlines, cost schedules and customer needs) (Leifer and Triscari, 1987). In addition, researchers should 
be given the opportunity to take an occasional break such as a sabbatical and to be involved in a variety of projects. To sum up, research needs to be very open and sometimes borders on chaos (Chiesa, 2001). On the other hand, development is much more subject to formal planning, with a clear definition of hierarchy and fixing project milestones and pressuring on deadlines (Chiesa and Frattini, 2007), so that any significant deviation of the plan should become the subject of formal discussion (Chiesa, 2001).

\section{Other features}

Research is considered a more complex activity (Leifer and Triscari, 1987; Chiesa and Frattini, 2007), involving the performance of more non-routine tasks than development and with a greater importance of discontinuous jumps in contrast with the more incremental nature of development (Karlsson et al., 2004). In addition, the time horizon is much longer in research than in development, where pressure to market usually constrains it between six months and two years. These factors underlie the perception that research is more uncertain than development (Nelson, 1959), although it has been recently highlighted that, actually, they suffer different kinds of uncertainty. While research faces a higher technical uncertainty (about a one in ten chance of success) and also a business risk (even a successful project could yield results that do not fit with the firm's business plan ${ }^{3}$ ), development involves a higher market risk, for example, a competitor entering the market earlier or the consumer not willing to buy the product (Van Ark et al, 2007).

\section{Empirical studies of research versus development}

During the 1980s, some authors pointed out that R\&D includes a myriad of activities and that an important task for researchers should be to analyze the determinants and impacts of this heterogeneity (see Mansfield, 1981 and Link, 1982, 1985) ${ }^{4}$. However, these authors themselves point out some limitations of their studies (especially related to the data and the analysis performed) and stress that results presented should be viewed as preliminary.

\footnotetext{
${ }^{3}$ Of course the results can be sold or the business plan adjusted but neither option is easily implemented in the short run as stressed by many of the R\&D managers (Van Ark et al., 2007).

${ }^{4}$ We do not include here the studies aimed at analyzing the impact of basic research, as this is not the aim of this paper. For a review of this strand of the literature, see Salter and Martin (2001).
} 
Table 1. Differences between research and development

\begin{tabular}{|c|c|c|}
\hline & Research & Development \\
\hline Purpose & $\begin{array}{l}\text { Acquire new knowledge } \\
\text { More theoretical (even if applied) }\end{array}$ & $\begin{array}{l}\text { Introduction of new or improved } \\
\text { process or product } \\
\text { Applied in nature }\end{array}$ \\
\hline $\begin{array}{l}\text { Type of } \\
\text { knowledge }\end{array}$ & $\begin{array}{l}\text { Analytical } \\
\text { Codified }\end{array}$ & $\begin{array}{l}\text { Synthetic } \\
\text { Tacit }\end{array}$ \\
\hline People & $\begin{array}{l}\text { More labour-intensive } \\
\text { Specialized } \\
\text { More qualified }\end{array}$ & $\begin{array}{l}\text { More material-intensive } \\
\text { Generalist } \\
\text { Less qualified }\end{array}$ \\
\hline Management & $\begin{array}{l}\text { Relative independence and links } \\
\text { with universities } \\
\text { Less hierarchy }\end{array}$ & $\begin{array}{l}\text { Integration and links with other } \\
\text { departments and customers } \\
\text { Formal planning }\end{array}$ \\
\hline Other features & $\begin{array}{l}\text { Complexity } \\
\text { Long term } \\
\text { Technical and business uncertainty }\end{array}$ & $\begin{array}{l}\text { Less complex } \\
\text { Short term } \\
\text { Market uncertainty }\end{array}$ \\
\hline
\end{tabular}

Mansfield (1981) uses a survey of 108 large US firms to analyze the determinants of the composition of R\&D expenditures and the effect of this composition on innovative output. This author distinguishes between four types of $R \& D$ expenditures: (i) $R \& D$ expenditures devoted to basic research, (ii) R\&D expenditures devoted to relatively long-term projects (projects lasting five or more years), (iii) $R \& D$ expenditures aimed at entirely new products and processes, and (iv) R\&D expenditures devoted to relatively risky projects (projects with less than a fifty-fifty estimated chance of success). One of the main results of this paper is that these four dimensions of $R \& D$ are not much related (when comparing firms within industries). Moreover, this author finds that larger firms are more oriented towards basic research, but he finds no evidence on the relationship between market concentration and the type of R\&D expenditure. Finally, regarding the effect of the composition of R\&D on innovative output, this author finds some correlation between the number of innovations and the proportion of basic research on total $R \& D$ expenditures.

Link (1982) analyzes the determinants of basic research, applied research and development for a sample of 275 firms belonging to Fortune 1000 list in the US. Firstly, this author finds that orientation to development is higher for firms operating in more concentrated markets and receiving more public funding. Secondly, firms with a higher level of profits are more 
oriented to applied research. Finally, orientation to basic research increases with diversification and profits and was higher for owner-managed firms.

Link (1985) adopts a dynamic perspective. This author finds that orientation to basic and long-term research is decreasing and he analyzes the determinants of this change for 146 very large US firms. He finds that managerial issues are important as firms with a more offensive strategy and central R\&D labs are also those more increasingly oriented towards basic and long-term research.

However, to our knowledge, in spite of the relevance of these papers and claims by their authors about the importance of studying the composition of $\mathrm{R} \& \mathrm{D}$, this topic has not received much attention (mainly due to the lack of appropriate data). In the last years, this topic has received growing interest due to the availability of new data from CIS surveys. Specifically, empirical studies are focused on analyzing the relationship between public funding and the composition of $R \& D^{5}$ (see Aerts and Thorwall, 2009; Clausen, 2009; and Czarnitzki et al., 2011).

Firstly, Aerts and Thorwall (2009) use a sample of 521 Belgian firms from two waves of the R\&D survey (2004 and 2006). These authors find that additionality of public funding exists in research but not in development.

Secondly, Clausen (2009) uses a sample of 1019 firms in Norway and distinguishes between subsidies for research and subsidies for development. This author also finds that there is additionality for research subsidies but not for development ones.

Finally, Czarnitzki et al. (2011) constructs an unbalanced panel from 1999 to 2007 including 952 Belgium firms. These authors analyze financial constraints associated with research and development activities. They find a higher effect of financial constraints on research (this activity is performed by firms showing more liquidity and less debt than those performing development).

More related to our study, we can quote two main examples: Czarnitzki et al. (2009) and Czarnitzki and Thorwarth (2010). Czarnitzki et al. (2009) analyzes the different impact of research and development on patents. They use an unbalanced panel of 122 Belgian firms

\footnotetext{
${ }^{5}$ Regarding related theoretical studies, for example, Banal-Estañol and Macho-Stadler (2010) present a model to analyze the effect of commercial and scientific incentives on the amount of time spent in research and development by researchers.
} 
from 1993 to 2003 . They find that the patent-R\&D relationship exhibits a premium for the portion of $\mathrm{R}$ in $\mathrm{R} \& \mathrm{D}$ although they warn about the explorative nature of the result due to the small size of the sample used.

On the other hand, Czarnitzki and Thorwarth (2010) focus on analyzing the effect of basic research on a firm's output depending on the technological intensity of the firm's industry. They find that basic research has a productivity premium when compared to applied research and development only for firms belonging to high-tech industries.

\section{Data and descriptive analysis}

\subsection{The database}

We use information from the Technological Innovation Panel (PITEC). PITEC is a statistical instrument for studying the innovation activities of Spanish firms over time. The data base is developed by the INE (The National Statistics Institute). The data come from the Spanish Community Innovation Survey (CIS).

The data base is placed at the disposal of researchers on the FECYT web site ${ }^{6}$. PITEC contains information for a panel of more than 12,000 firms from 2003 to 2008, for the moment. PITEC consists of several subsamples, the most important of which are a sample of firms with 200 or more employees and a sample of firms with intramural R\&D expenditures. Both subsamples have quite broad coverage. A more detailed description can be found on the FECYT web site.

PITEC has three main advantages for this study. Firstly and most important, this data base has detailed information about firms' R\&D activities. Specifically, it allows the differentiation between research and development expenditures ${ }^{7}$. This information, seldom available, is essential to this study.

Secondly, PITEC is a CIS-type data base. CIS data are widely used both by policy observers to provide innovation indicators and trend analyses, and by economists to analyze a variety of topics related to innovation. Therefore, throughout this study, we use widely

\footnotetext{
${ }^{6}$ http://icono.fecyt.es/contenido.asp?dir=05)Publi/AA)panel. To observe confidentiality, an anonymized version of the data is available on the web site. The anonymization procedure applied at the PITEC is described at the web page.

${ }^{7}$ Specifically, this differentiation between research and development expenditures refers only to current R\&D expenditures. We assume that these weights can be extended to total $R \& D$ expenditures (including both current and capital expenditures). In our sample, current R\&D expenditures account for approximately $80 \%$ of total R\&D expenditures.
} 
accepted innovation indicators and variables. For a review of CIS-based studies, see, for example, van Beers et al. (2008) and Mairesse and Mohnen (2010).

Thirdly, PITEC is designed as a panel data survey. This fact allows us to mitigate many of the problems related to studies using CIS data, such as the simultaneity between input and outputs by lagging explanatory variables.

In this paper, we use information from PITEC for the period $2005-2008^{8}$, and we restrict our attention to manufacturing firms ${ }^{9}$. Finally, we use a constant sample of 4,168 firms for which we have data for each year in the period 2005-2008.

\subsection{Research and Development: A descriptive analysis}

At this point, we briefly describe intramural $R \& D$ expenditures of Spanish manufacturing firms during the period 2005-2008. Specifically, we focus on the decomposition of total expenditures between expenditures in research activities and development activities. As we said in Section 2, we define research expenditures as the sum of expenditures in basic and applied research.

First, we identify firms performing both research and development, firms performing only research and firms performing only development during the period 2005-2008 (see Table $2)^{10}$. It should be noted that less than half of the firms perform both research and development, while firms performing only development activities are more common than those performing only research. This pattern is stable across industries with the exception of the low-tech sector where the percentage of firms performing only research is similar to the percentage of firms performing only development.

\footnotetext{
${ }^{8}$ Due to enlargements of the sample of firms performing intramural R\&D in 2004 and 2005, we do not use the data for the years 2003 and 2004.

${ }^{9}$ R\&D performed by manufacturing and service firms shows many differences (see, for example, Sirilli and Evangelista, 1998).

${ }^{10}$ We find an important decrease in the number of R\&D performers during the period 2005-2008 in the sample employed. This decrease is mainly due to firms which report performing R\&D occasionally.
} 
Table 2. Firms with R\&D expenditures by year (number and percentage of firms)

\begin{tabular}{ccccc}
\hline & 2005 & 2006 & 2007 & 2008 \\
\hline Manufacturing firms & 3,795 & 3,446 & 3,268 & 3,087 \\
with $R$ and $D$ & $43.5 \%$ & $42.5 \%$ & $41.1 \%$ & $41.7 \%$ \\
only $R$ & $23.6 \%$ & $23.0 \%$ & $23.6 \%$ & $24.0 \%$ \\
only $D$ & $32.9 \%$ & $34.5 \%$ & $35.3 \%$ & $34.3 \%$ \\
\hline Low-tech firms & 1002 & 874 & 837 & 776 \\
with $R$ and $D$ & $39.8 \%$ & $38.9 \%$ & $37.6 \%$ & $39.2 \%$ \\
only $R$ & $30.8 \%$ & $30.1 \%$ & $30.0 \%$ & $30.4 \%$ \\
only $D$ & $29.4 \%$ & $31.0 \%$ & $32.4 \%$ & $30.4 \%$ \\
\hline Medium-low tech firms & 936 & 839 & 767 & 717 \\
with $R$ and $D$ & $41.5 \%$ & $39.2 \%$ & $37.4 \%$ & $37.3 \%$ \\
only $R$ & $20.8 \%$ & $20.9 \%$ & $21.8 \%$ & $23.8 \%$ \\
only $D$ & $37.7 \%$ & $39.9 \%$ & $40.8 \%$ & $38.9 \%$ \\
\hline Medium-high tech firms & 1395 & 1297 & 1240 & 1181 \\
with $R$ and $D$ & $44.7 \%$ & $44.6 \%$ & $44.2 \%$ & $43.5 \%$ \\
only $R$ & $21.9 \%$ & $21.3 \%$ & $21.0 \%$ & $20.2 \%$ \\
only $D$ & $33.5 \%$ & $34.2 \%$ & $34.8 \%$ & $36.3 \%$ \\
\hline High-tech firms & 462 & 436 & 425 & 413 \\
with $R$ and $D$ & $51.9 \%$ & $49.5 \%$ & $44.9 \%$ & $48.9 \%$ \\
only $R$ & $18.8 \%$ & $18.2 \%$ & $22.4 \%$ & $23.0 \%$ \\
only $D$ & $29.3 \%$ & $32.3 \%$ & $32.7 \%$ & $28.1 \%$ \\
\hline
\end{tabular}

Table 3 shows the weight of research expenditures and development expenditures in the total R\&D expenditures by year. Firms spend slightly more on development, and this result is consistent over the years analyzed. Development expenditures account for about 55\% of intramural R\&D expenditures, while research expenditures account for about $45 \%$ of intramural $R \& D$ expenditures. These figures point to a high orientation to research (in relative terms) by Spanish firms. For example, in France, firms devote $31.7 \%$ of R\&D expenses to research (Bertrand, 2009). In Belgium, this figure is around 33\% (Czarnitzki et al., 2011), while NSF estimated it to be around 25\% in the US in 2001 (Bercovitz and Feldman 2007). 
Table 3. Percentage of $R$ expenditures and $D$ expenditures by year ${ }^{1}$

\begin{tabular}{lccccc}
\hline & 2005 & 2006 & 2007 & 2008 & Mean \\
\hline R expenditures & 46.1 & 44.9 & 44.4 & 45.1 & 45.1 \\
D expenditures & 53.9 & 55.1 & 55.6 & 54.9 & 54.9 \\
\hline
\end{tabular}

${ }^{1}$ Firms with R\&D expenditures.

Surprisingly, firms belonging to low technological sectors spend slightly more on research than on development (see Table 4). For the rest of the sectors analyzed, development expenditures are higher than research expenditures. However, this result for low-tech firms should be viewed with some caution as they are less intensive in both research and development. This fact is pointed out in Table 5.

Table 4. Percentage of $R$ expenditures and $D$ expenditures by sector ${ }^{1}$ (\% with respect to total R\&D expenditures)

\begin{tabular}{lcc}
\hline & R expenditures & D expenditures \\
\hline Low-tech firms & 50.7 & 49.3 \\
Medium-low tech firms & 41.3 & 58.7 \\
Medium-high tech firms & 43.5 & 56.5 \\
High-tech firms & 45.9 & 54.1 \\
Manufacturing firms & 45.1 & 54.9 \\
\hline
\end{tabular}

${ }^{1}$ Firms with R\&D expenditures. Weighted mean of years 2005, 2006, 2007 and 2008.

Table 5 shows the ratio of intramural R\&D expenditures over total turnover by industry, and its decomposition between the ratio of research expenditures over total turnover and the ratio of development expenditures over total turnover. As expected, both ratios are much higher for firms belonging to high-technology industries (1.96\% and $2.28 \%$, respectively). In the case of research expenditures, this ratio is almost six times higher in high-tech industries than in low-tech industries, while for development expenditures, it is seven times higher in high-tech industries than in low-tech ones. 
Table 5. Ratio of intramural R\&D expenditures over total turnover ${ }^{1}$ (\% with respect to sales)

\begin{tabular}{lccc}
\hline & $\frac{\mathrm{R} \text { expenditures }}{\text { Total turnover }}$ & $\frac{\mathrm{D} \text { expenditures }}{\text { Total turnover }}$ & $\frac{\text { R\&D expenditures }}{\text { Total turnover }}$ \\
\hline Low-tech firms & 0.34 & 0.33 & 0.67 \\
Medium-low tech firms & 0.26 & 0.37 & 0.63 \\
Medium-high tech firms & 0.51 & 0.67 & 1.18 \\
High-tech firms & 1.96 & 2.28 & 4.24 \\
Manufacturing firms & 0.59 & 0.72 & 1.31 \\
\hline
\end{tabular}

${ }^{1}$ Firms with R\&D expenditures. Weighted mean of years 2005, 2006, 2007 and 2008.

\section{Econometric specification}

We estimate a modified "knowledge production function" where some innovation output (I) depends on research and development expenditures, as well as on Z, which is a vector of controls. Thus for each firm i:

$I_{i,(06-08)}=G\left(a+\alpha\right.$ Rintensity $_{i,(05-07)}+\beta$ Dintensity $\left._{i,(05-07)}+\varphi Z_{i,(05-07)}+\varepsilon_{i}\right)$

,where $G$ is a linear or a non-linear function (depending on the dependent variable considered).

Specifically, we focus on three different innovation outputs: (i) Patent applications; (ii) Technological innovations (measured by the introduction of product and process innovations); and (iii) Innovative sales.

Given that, due to the design of the CIS, innovation outputs refer to a three-year period, we consider the innovation outputs for the period 2006-2008 (which correspond to the answers from the questionnaire of the year 2008) to be dependent variables. In defining the explanatory variables, we use yearly information from the questionnaires from the years 2005, 2006 and 2007. For example, in obtaining research and development expenditures, we sum the expenditures reported by the firm for the years 2005, 2006 and 2007 (which correspond to the answers from the questionnaires from the years 2005, 2006 and 2007, respectively $)^{11}$. Using this approach, we mitigate simultaneity and endogeneity problems inherent to cross-section analysis using CIS data in a single year (i.e., in many papers,

\footnotetext{
${ }^{11}$ As a robustness check, we also define explanatory variables using information from 2005 and 2006. Results are shown in Section 6.
} 
outputs which refer to a three-year period are explained using independent variables which refer only to the last year of the period).

\subsection{Sample of firms and variables used in the estimation}

\section{Sample of firms}

As we said before, our panel data set comes from PITEC for the years 2005 to 2008, which allows us to use values of the explanatory variables from the period 2005-2007 to explain the existence of different innovation outputs in 2006-2008. Given this setup, we restrict our attention to those manufacturing firms presenting a positive amount spent on intramural R\&D in at least one year during the period 2005-2007. This selection should not be problematic since several studies (see for example, Mairesse and Cuneo, 1984; and Crepon and Mairesse, 1993) show that there is not an important selection bias when using only R\&D performers to analyze the relationship between $R \& D$ and productivity. Moreover, this selection is driven by the aim of the study: to analyze the different impacts of R and D. The final sample used in the estimation includes 4,024 firms observed for the period 2005 to 2008.

\section{Dependent variables}

We focus on three different innovation outputs: patents, technological innovation and innovative sales. These three types of outputs are located along an axis reflecting distance to market. Patents are the results of inventive activity, and thus they can be seen as an intermediate output. Technological innovation (new products and processes) are technological outputs of the innovation process. Finally, sales from innovative products constitute an economic indicator of innovation success.

Firstly, we have information on whether the firm has applied for patents (the extensive dimension) and on the number of patent applications (the intensive dimension). Specifically, we define the intensive measure as the number of patent applications per 100,000 employees (in logs). Secondly, in order to measure technological innovation, we have information on whether the firm has introduced a product or process innovation. In the case of product innovation, we consider only the introduction of products new to the firm's market. Finally, to measure innovative sales, we use the ratio between sales due to new-tothe-market products and total number of employees (in logs). 


\section{Explanatory variables}

This paper is focused on analyzing the differentiated effect of research and development on innovation results. In this sense, we distinguish between research intensity ( $R$ intensity in equation (1)) expressed as the ratio of research expenditures over the total number of employees (in logs) and development intensity ( $D$ intensity in equation (1)) expressed as the ratio of development expenditures over the total number of employees (in logs).

In addition, in each regression, we control for several firms' specific characteristics. As controls, denoted by $\mathrm{Z}$ in equation (1), we include firm size (measured by the log of total turnover), external R\&D intensity (note that data do not allow us to distinguish between external ' $R$ ' and external ' $D$ '), cooperation, spillovers and the existence of cost and information barriers to innovation. Detailed definitions of all variables employed can be found in Appendix A.

Note that, as we said before, we use information from the most relevant explanatory variables for the period 2005-2007. Therefore, in the case of these variables (research intensity, development intensity, firm size and external R\&D intensity), we are using their weighted means for the period 2005-2007 as explanatory variables ${ }^{12}$. For example:

Research intensity $\mathrm{i}_{i, 05-07}=\log \left(\frac{\text { research expenditures }_{\mathrm{i}, 05}+\text { research expenditures }_{\mathrm{i}, 06}+\text { research expenditures }_{\mathrm{i}, 07}}{\text { employees }_{\mathrm{i}, 05}+\text { employees }_{\mathrm{i}, 06}+\text { employees }_{\mathrm{i}, 07}}\right)$

For the rest of the explanatory variables, we use the data for the year 2005.

To analyze differences among industries, we consider industry-specific relationships between inputs and outputs. In doing this, we include interaction terms between our variables of interest (research intensity and development intensity) and industry dummies representing the technological intensity of the industry. We distinguish between four industries according to technological intensity following the OECD classification (OECD $2005)^{13}$.

\footnotetext{
${ }^{12}$ When we define these variables with information from 2005 and 2006, we use their weighted means for the period 2005-2006. In this case, we define the sample restricting our attention to those manufacturing firms presenting a positive amount spent on intramural R\&D in at least one year during the period 2005-2006.

${ }^{13}$ The OECD classification consists of four categories of industries: Low-Tech, Low-medium Tech, Medium-high Tech and High-Tech. Detailed definitions of these industries can be found in Appendix A.
} 
In this sense, a strand of literature has analyzed the industry differences in terms of several characteristics, such as opportunity and appropriability conditions, cumulativeness or knowledge bases (for a review, see Malerba, 2002; 2007). Moreover, some authors have pointed out the analysis of industry peculiarities of the relationships between inputs and outputs of innovation as a crucial future line of research (Mairesse and Mohnen, 2010).

Moreover, as a robustness check, we use an alternative industry classification: the Pavitt taxonomy. This classification consists of four categories of industries according to sources of technology, requirements of the users and appropriability regime (see Pavitt 1984) ${ }^{14}$.

\subsection{Estimation method}

\section{Patent equation}

In this case, we are interested in estimating the determinants affecting both the firm's capacity to apply for patents and the number of patent applications (for those firms active in patenting). Using the notation in equation (1), we can write:

$$
\begin{aligned}
& \text { Pat }_{i,(06-08)}=\Phi\left(a_{1}+\alpha_{1} \text { R }_{\text {intensity }_{i,(05-07)}}+\beta_{1} D \text { intensity }_{i,(05-07)}+\varphi_{1} Z_{i,(05-07)}+\varepsilon_{1 i}\right) \\
& \text { PatInt }_{i,(06-08)}=a_{2}+\alpha_{2} \text { R }_{\text {intensity }_{i,(05-07)}}+\beta_{2} \text { D }_{\text {intensity }_{i,(05-07)}}+\varphi_{2} Z_{i,(05-07)}+\varepsilon_{2 i}
\end{aligned}
$$

, where $\Phi$ is the normal standard c.d.f., Pat is a dummy variable indicating whether or not firm $i$ applies for patents and PatInt is the number of patent applications per 100,000 employees (in logs).

We estimate equation (2) using a probit model for the whole sample and equation (3) by OLS for the sub-sample of firms with at least one patent application. Equation (3) may be seen as the second equation of a two-part model where the first part is equation (2) (for a further discussion of this topic, see Wooldridge, 2002, Chapter 16). By applying this method, we allow different mechanisms to determine the probability of patenting and the patent intensity. However, the results of equation (3) will apply only to patenting firms and cannot be extended to the whole sample ${ }^{15}$.

\footnotetext{
${ }^{14}$ Pavitt taxonomy consists of four categories of industries: Supplier-Dominated, Scale-Intensive, Specialized-Suppliers and Sciencebased. Detailed definitions of these industries can be found in Appendix A.

${ }^{15}$ If $\mathrm{R}$ and D show positive coefficients in the first part, estimates would show a downward bias if extended to the whole sample. See Angrist and Pishke (2008), Chapter 3 for details. An alternative approach would be to use a generalized tobit. This would be the same as assuming missing values in the number of patents for the non-patenting firms. However, we observe that they have zero patents.
} 
Moreover, we also estimate equation (3) using Quantile regression. This procedure examines conditional changes in different points of the distribution by minimizing a weighted sum of absolute deviations. This method allows us to know more about the entire distribution of patent application intensity. Specifically, we use the whole sample and present the results for the 90th, 94th and 98th percentiles of the distribution. These percentiles are chosen on empirical grounds as the ninth decile is the first one with a positive value of patent intensity.

\section{Technological innovation equation}

At this point, we have two equations of interest. Again, using the notation in equation (1), we can write:

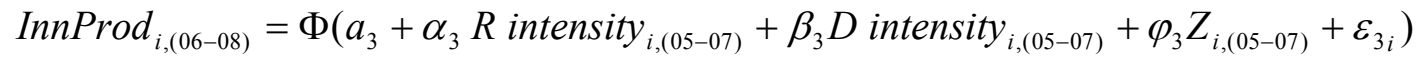

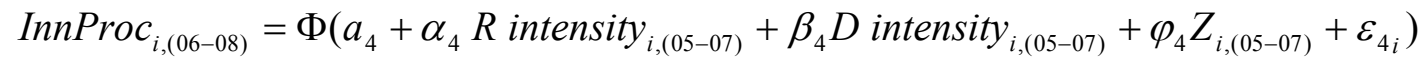

, where $\Phi$ is the normal standard c.d.f. and InnProd and InnProc are dummy variables indicating whether or not firm $i$ has introduced product or process innovations, respectively.

We estimate equations (4) and (5) using two separate probit models. Moreover, we also estimate a joint model for InnProd and InnProc using a bivariate probit model.

\section{Innovative sales equation}

In this case, the equation of interest is:

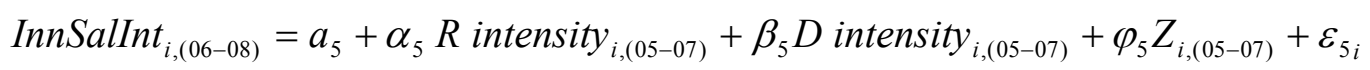

,where InnSalInt is the ratio between sales due to new-to-the-market products and total number of employees (in logs).

We estimate equation (6) by OLS for the sub-sample of firms with product innovations. This equation may be seen as the second equation of a two-part model, where the first part is equation (4).

Again, in order to deeply analyze the distribution of innovative sales, we estimate equation (6) using Quantile regression. In this case, we present the results for the 70th, 80th and 90th 
percentiles of the distribution. Again, this selection is based on empirical grounds, as $56 \%$ of firms do not show positive innovative sales.

\section{Results and discussion}

In this section, we present the results of the differentiated effect of research and development on innovation outputs. The first three sections show the baseline results for patent application, technological innovation and innovative sales without focusing on industry differences. Section 6.4 presents some robustness checks. Finally, in Section 6.5, we focus on analyzing the effect of research and development on innovation results by the firm's industry.

\subsection{Patent application}

First, we analyze the differentiated effect of research and development on patent application. Regression $a$ in Table 6 shows the estimated coefficients of the determinants of patent application for a probit model for the whole sample of firms. We find that both research and development have a positive effect on the probability of patenting. Most interesting, we find no difference between the effects of these two types of expenditures.

Estimates $b$ to $e$ in Table 6 show the results for the intensive dimension of patents. Firstly, Estimate $b$ shows the OLS results for the sample of firms with at least one patent application. We find that both research and development expenditures seem to have no significant effect on patent application intensity. Again, the difference between the effects of both types of expenditures is not significant.

Secondly, estimates $c, d$ and $e$ in Table 6 present Quantile regression results. These results confirm that there are no differences between the effects of research and development on patent intensity. Most interesting and in contrast with the OLS results, we find that both research and development have a positive and significant effect on patent intensity. 
Table 6. The differentiated effect of Research and Development on patent application

\begin{tabular}{|c|c|c|c|c|c|c|c|c|c|c|}
\hline \multirow[b]{3}{*}{$R$ intensity } & \multicolumn{2}{|c|}{$\begin{array}{c}\text { (a) } \\
\text { Probability of patent } \\
\text { application }\end{array}$} & \multicolumn{2}{|c|}{ (b) } & \multicolumn{4}{|c|}{$\begin{array}{l}\text { Number of patent applications } \\
\text { (Patent application intensity) }\end{array}$} & \multicolumn{2}{|c|}{ (e) } \\
\hline & \multicolumn{2}{|c|}{ Probit } & \multicolumn{2}{|c|}{ OLS } & \multicolumn{2}{|c|}{$\begin{array}{c}\text { Quantile regression } \\
\left(90^{\text {th }} \text { percentile }\right)\end{array}$} & \multicolumn{2}{|c|}{$\begin{array}{c}\text { Quantile regression } \\
\left(94^{\text {th }} \text { percentile }\right)\end{array}$} & \multicolumn{2}{|c|}{$\begin{array}{c}\text { Quantile regression } \\
\left(98^{\text {th }} \text { percentile }\right)\end{array}$} \\
\hline & $0.011^{* * *}$ & $(0.002)$ & 0.021 & $(0.013)$ & $0.250^{* * *}$ & $(0.050)$ & $0.107^{* * *}$ & $(0.027)$ & $0.106^{* * 1}$ & $(0.036)$ \\
\hline$D$ intensity & $0.011^{* * *}$ & $(0.002)$ & 0.016 & $(0.016)$ & $0.262^{* * *}$ & $(0.061)$ & $0.118^{* * *}$ & $(0.033)$ & $0.123^{* *}$ & $(0.042)$ \\
\hline Size & $0.018^{* * *}$ & $(0.003)$ & $-0.541^{* * *}$ & $(0.029)$ & -0.114 & $(0.092)$ & $-0.372^{* * *}$ & $(0.050)$ & $-0.412^{* * *}$ & $(0.069)$ \\
\hline External $R \& D$ intensity & $0.011^{* * *}$ & $(0.002)$ & 0.017 & $(0.013)$ & $0.255^{* * *}$ & $(0.050)$ & $0.105^{* * *}$ & $(0.027)$ & $0.078^{*}$ & $(0.035)$ \\
\hline Cooperation & $0.032^{* *}$ & $(0.012)$ & -0.168 & $(0.088)$ & 0.417 & $(0.336)$ & 0.071 & $(0.179)$ & -0.004 & $(0.237)$ \\
\hline Information factors & 0.014 & $(0.027)$ & 0.110 & $(0.191)$ & -0.138 & $(0.744)$ & 0.126 & $(0.401)$ & 0.155 & $(0.552)$ \\
\hline Cost factors & -0.007 & $(0.022)$ & -0.268 & $(0.158)$ & -0.249 & $(0.592)$ & -0.032 & $(0.323)$ & -0.550 & $(0.440)$ \\
\hline Spillovers & $0.112^{* * *}$ & $(0.021)$ & 0.034 & $(0.183)$ & $3.368^{* * *}$ & $(0.551)$ & $0.708^{*}$ & $(0.302)$ & 0.667 & $(0.416)$ \\
\hline Medium-low industry & $0.072^{* * *}$ & $(0.019)$ & 0.101 & $(0.123)$ & $2.552^{* * *}$ & $(0.415)$ & $0.826^{* * *}$ & $(0.222)$ & 0.419 & $(0.290)$ \\
\hline Medium-high industry & $0.086^{* * *}$ & $(0.017)$ & 0.121 & $(0.110)$ & $2.923^{* * *}$ & $(0.385)$ & $0.995^{* * *}$ & $(0.205)$ & 0.361 & $(0.269)$ \\
\hline High industry & $0.102^{* * *}$ & $(0.025)$ & 0.170 & $(0.145)$ & $2.201^{* * *}$ & $(0.536)$ & $1.233^{* * *}$ & $(0.279)$ & 0.525 & $(0.362)$ \\
\hline Number of firms & \multicolumn{2}{|c|}{4,024} & \multicolumn{2}{|c|}{647} & \multicolumn{2}{|c|}{4,024} & \multicolumn{2}{|c|}{4,024} & \multicolumn{2}{|c|}{4,024} \\
\hline R-squared & & & & & & & & & & \\
\hline Log-Likelihood & \multicolumn{2}{|c|}{$-1,621.406$} & & & & & & & & \\
\hline Pseudo R-squared & \multicolumn{2}{|c|}{0.086} & & & \multicolumn{2}{|c|}{0.083} & \multicolumn{2}{|c|}{0.057} & \multicolumn{2}{|c|}{0.063} \\
\hline Test $R=D^{1}$ & \multicolumn{2}{|c|}{0.921} & \multicolumn{2}{|c|}{0.805} & \multicolumn{2}{|c|}{0.853} & \multicolumn{2}{|c|}{0.773} & \multicolumn{2}{|c|}{0.728} \\
\hline
\end{tabular}

Robust standard errors in parentheses. $* * *$ significant at $1 \%, * *$ significant at $5 \%$, *significant at $10 \%$

Estimate (a) shows the marginal effects of the independent variables.

${ }^{1} p$-value from a test of equality of estimated coefficients of $R$ intensity and $D$ intensity. 
To sum up, we find no differences between the effect of research and development on both the probability of applying for patents and the number of patent applications. This result differs from that of Czarnitzki et al. (2009). These authors find that the weight of research on total R\&D expenditures positively affected the number of patents. However, we can point out four important differences between our study and Czarnitzki et al. (2009). The first difference is the sample size. In this sense, we use a sample of 4,268 firms, in contrast with the 122 firms used by Czarnitzki et al. (2009). Second, they analyze the effect of contemporaneous R\&D expenditures on the number of patents filed. Thirdly, they use panel data techniques to control for unobservable individual heterogeneity. Finally, they use an absolute measure (number of patents), while we use a relative measure (number of patents weighted by firm size).

\subsection{Technological innovation}

Table 7 shows the differentiated effect of research and development on both product and process innovation. Estimates $a$ and $b$ show separate probit models results for product and process innovation, while estimate $c$ shows the results of a bivariate probit model. Results for separate probits and bivariate probit are very similar, although the hypotheses that $\rho=0$ is rejected, suggesting that the bivariate probit is more adequate.

We find that research and development have a significant and positive effect on both product and process innovation. Research intensity has a similar effect on both types of technological innovation, while the effect of development expenditures is much higher on the probability of introducing product innovations.

Comparing the effect on each type of innovation, we find that development activities are more important than research activities in introducing product innovations. In particular, development intensity exhibits a 50\% higher coefficient than research intensity. For their part, research activities have a 30\% higher effect on introducing process innovation than development activities. These results might suggest that development expenditures are highly relevant to obtaining new products and are not usually used to obtain new processes. However, research activities seem to be very helpful also in obtaining new processes. This result is of great importance for shedding light on the sources of process innovations. As 
some authors have highlighted, process innovation has received less attention than product innovation, although it is crucial for productivity improvements (Reichstein and Salter, 2006).

Furthermore, evidence on the relationship between R\&D and process innovation is not conclusive. Some authors find a positive and important effect of R\&D on process innovation (Mairesse and Mohnen, 2005; Reichstein and Salter, 2006). Meanwhile, other studies find no evidence supporting this relationship (Martinez-Ros, 2000; Rouvinen 2002) or even a negative one (Conte, 2009). Our results suggest that both activities have a positive effect on process innovation, although the effect of research seems higher.

Table 7. The differentiated effect of Research and Development on technological innovation

(a) (b) (c) (d)

Product innovation Process innovation Product innovation Process innovation

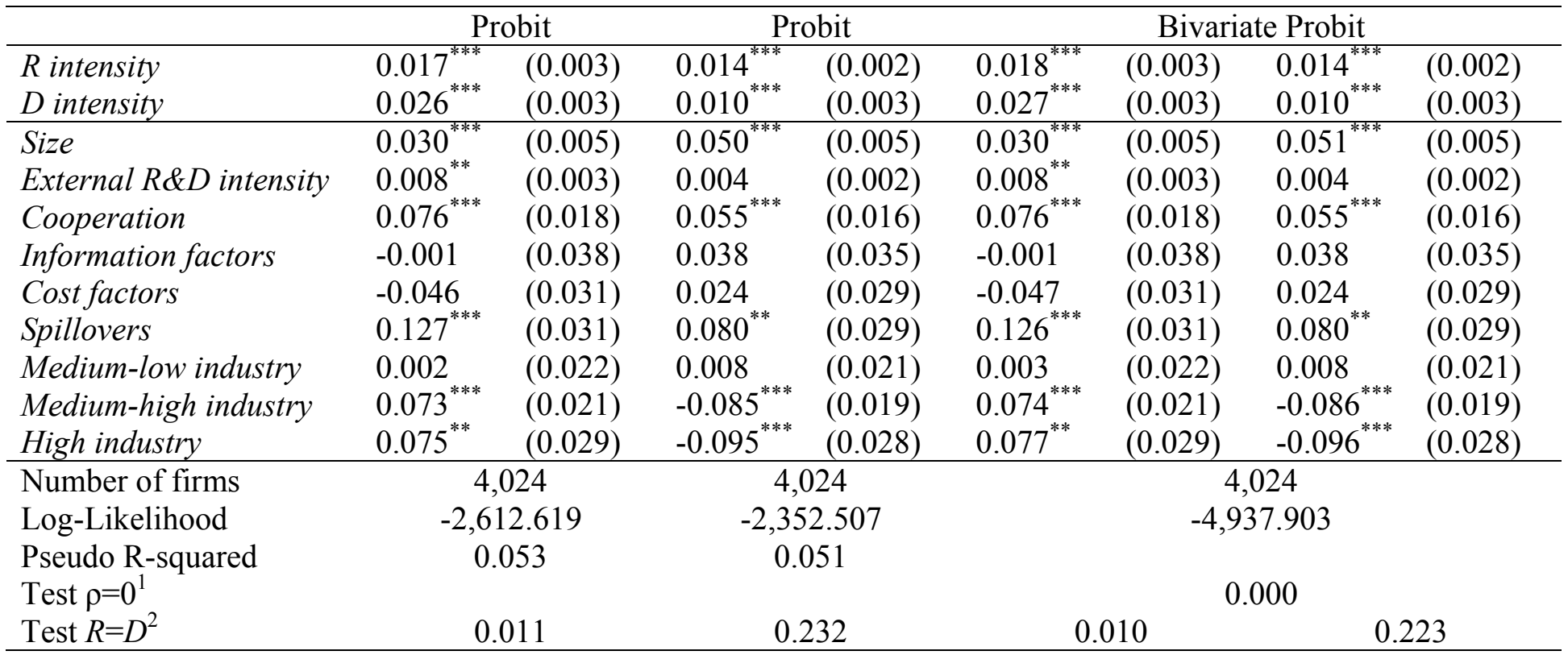

Robust standard errors in parentheses. ${ }^{* * *}$ significant at $1 \%,{ }^{* *}$ significant at $5 \%$, *significant at $10 \%$.

Coefficients are the marginal effect of the independent variable.

${ }_{2}^{1} p$-value from a test of $\rho=0$.

${ }^{2} p$-value from a test of equality of estimated coefficients of $R$ intensity and $D$ intensity. 


\subsection{Innovative sales}

The last innovation output analyzed is sales due to new-to-the-market products. Regression $a$ in Table 8 shows OLS estimates of the effect of research and development on innovative sales for the sample of firms with product innovations. Again, both types of innovation expenditures have a positive and significant effect. In this case, the effect of development expenditures on innovative sales is slightly higher than the effect of research expenditures. The estimated elasticities of innovative sales with respect to development and research intensities are 0.059 and 0.046 , respectively.

Table 8. The differentiated effect of Research and Development on innovative sales

\begin{tabular}{|c|c|c|c|c|c|c|c|c|}
\hline & & & $\begin{array}{l}\text { Quantile } \\
\left(70^{\text {th }} \mathrm{p}\right.\end{array}$ & $\begin{array}{l}\text { gression } \\
\text { entile) }\end{array}$ & $\begin{array}{l}\text { Quantile } \\
\left(80^{\text {th }} \mathrm{p}\right.\end{array}$ & $\begin{array}{l}\text { gression } \\
\text { entile) }\end{array}$ & $\begin{array}{c}\text { Quantil } \\
\left(90^{\text {th }}\right.\end{array}$ & $\begin{array}{l}\text { egression } \\
\text { centile) }\end{array}$ \\
\hline$R$ intensity & $0.048^{* * *}$ & $(0.013)$ & $0.186^{* * *}$ & $(0.030)$ & $0.108^{* * *}$ & $(0.019)$ & $0.068^{* * * *}$ & $(0.017)$ \\
\hline$D$ intensity & $0.067^{* * *}$ & $(0.016)$ & $0.407^{* * *}$ & $(0.035)$ & $0.181^{* * *}$ & $(0.023)$ & $0.118^{* * *}$ & $(0.020)$ \\
\hline Size & $0.153^{* * *}$ & $(0.025)$ & $0.383^{* * *}$ & $(0.057)$ & $0.222^{* * *}$ & $(0.037)$ & $0.202^{* * * *}$ & $(0.031)$ \\
\hline External $R \& D$ intensity & 0.012 & $(0.012)$ & $0.080^{* *}$ & $(0.030)$ & $0.059^{* *}$ & $(0.019)$ & $0.052^{* *}$ & $(0.017)$ \\
\hline Cooperation & -0.094 & $(0.081)$ & 0.284 & $(0.206)$ & 0.166 & $(0.132)$ & 0.037 & $(0.113)$ \\
\hline Information factors & -0.026 & $(0.175)$ & -0.282 & $(0.435)$ & -0.259 & $(0.278)$ & -0.227 & $(0.236)$ \\
\hline Cost factors & 0.218 & $(0.152)$ & -0.024 & $(0.356)$ & 0.104 & $(0.229)$ & 0.229 & $(0.197)$ \\
\hline Spillovers & -0.134 & $(0.145)$ & $0.695^{*}$ & $(0.354)$ & 0.215 & $(0.227)$ & 0.005 & $(0.198)$ \\
\hline Medium-low industry & 0.074 & $(0.113)$ & 0.000 & $(0.255)$ & 0.264 & $(0.163)$ & 0.097 & $(0.138)$ \\
\hline Medium-high industry & 0.129 & $(0.099)$ & $0.663^{* *}$ & $(0.236)$ & $0.541^{* * *}$ & $(0.151)$ & 0.159 & $(0.128)$ \\
\hline High industry & -0.173 & $(0.133)$ & 0.197 & $(0.329)$ & 0.095 & $(0.210)$ & -0.134 & $(0.176)$ \\
\hline Number of firms & & & & & & & & \\
\hline R-squared & & & & & & & & \\
\hline Pseudo R-squared & & & & & & & & \\
\hline Test $R=D^{1}$ & & & & & & & & \\
\hline
\end{tabular}

Robust standard errors in parentheses.

$* * *$ significant at $1 \%, * *$ significant at $5 \%$, *significant at $10 \%$.

${ }^{1} p$-value from a test of equality of estimated coefficients of $R$ intensity and $D$ intensity.

Estimates $b, c$ and $d$ in Table 8 present the results for the 70th, 80th and 90th percentiles, respectively. They clearly show that development intensity has a significantly greater effect than research intensity. At the $70^{\text {th }}$ percentile, the effect of development intensity is more than double the effect of research intensity, while at the $80^{\text {th }}$ and $90^{\text {th }}$ percentiles it is $70 \%$ greater. That is, the impact of development on sales from new-to-the-market products is 
much higher than the impact of research even for the more innovation-intensive points of the distribution.

\subsection{Robustness checks}

We apply two robustness checks to verify our results. The first test is related to the lag used to define our main explanatory variables. For now, we are using research and development expenditures for the period 2005-2007 to explain innovation outputs for the period 20062008. In this sense, we may still have too much overlapping between the periods considered. In solving this problem, we define research intensity, development intensity, firm size and external R\&D intensity using information for 2005 and 2006. In this case, we use past and contemporaneous values of these explanatory variables (in 2005 and 2006) to explain innovation outputs (in 2006-2008). Tables A1, A2 and A3 in Appendix B show the results for patent application, technological innovation and innovative sales, respectively. We find that the results are very similar to those presented before, although, in general, we obtain less precise estimations and estimated coefficients are smaller.

The second robustness check is related to the definition of the sample of interest. For the moment, we have focused on firms with intramural R\&D expenditures in at least one year during the period 2005-2007. Therefore, we do not distinguish between occasional R\&D performers and continuous $R \& D$ performers (i.e., firms with intramural R\&D expenditures in 2005, 2006 and 2007). This second test analyzes the differentiated effect of research and development on innovation outputs, focusing on a sample of 3,027 continuous R\&D performers (see Tables A4, A5 and A6 in Appendix B). Again, results are very similar to those presented in Sections 6.1, 6.2 and 6.3. This finding might suggest that our results are valid for the whole population of $R \& D$ performers without distinguishing between occasional and continuous performers.

\subsection{Industry level results}

In this section, we analyze the effect of research and development on innovation results by the firm's industry. In doing this, we use the interactions between research and development intensities and industry dummies indicating technological intensity (following 
the OECD classification) as explanatory variables. As we said in Section 5.1, in defining industry dummies, we also use the Pavitt taxonomy as a robustness check.

Firstly, following the OECD classification, we allow research intensity and development intensity to be interacted with dummies for belonging to a low-tech industry, to a lowmedium tech industry, to a medium-high industry or to a high-tech industry (denoted by -lt, $-l m t,-m h t$ and $-h t$, respectively). For example, $R$ intensity-lt is the interaction between the firm's research intensity and a dummy variable for belonging to a low-tech industry.

Secondly, using the Pavitt taxonomy, we allow research intensity and development intensity to interact with dummies for belonging to a supplier-dominated industry, to a scale-intensive industry, to a specialized-suppliers industry or to a science-based industry (denoted by $-s d,-s i$, -ss and -sb, respectively). For example, $R$ intensity-sd is the interaction between the firm's research intensity and a dummy variable for belonging to a supplierdominated industry.

\subsubsection{OECD Classification}

We find that the general pattern of results does not change across the industries considered (see Tables 9, 10 and 11) ${ }^{16}$. Firstly, research and development intensities have a similar effect on patent application. Secondly, development expenditures have a higher effect on both the introduction of product innovations and, especially on sales due to these new products. Finally, research expenditures have a greater effect on process innovation. These results hold across industries, although differences between the effects of $R$ intensity and $D$ intensity are usually not significant (see Table A7).

Regarding differences by industry, we find that the effect of research and development intensities on the probability of patent application is greater on medium-high tech and hightech industries than on low-tech and medium-low tech industries (see estimate $a$ in Table 9). This result might suggest that both research and development are more oriented to obtaining patents in industries intensive in technology, probably as a consequence of the existence of different appropriability regimes among industries.

\footnotetext{
${ }^{16}$ Table A7 in Appendix B shows the results for tests of equality of estimated coefficients of $R$ intensity and $D$ intensity).
} 
All the interaction variables lose their significance when we analyze the determinants of the number of patent applications (see estimate $b$ in Table 9). However, Quantile regressions (see estimates $c, d$ and $e$ in Table 9) mostly restore their significance. We find a big effect of both $\mathrm{R}$ and $\mathrm{D}$ in low-tech sectors in the $90^{\text {th }}$ and $94^{\text {th }}$ percentiles of the distribution, while, $\mathrm{R}$ and especially $\mathrm{D}$ have a big effect for high-tech sectors in the $98^{\text {th }}$ percentile.

When analyzing the introduction of technological innovations, firstly, we find that research is more conducive to product innovations in low-tech industries. In fact, this type of innovation expenditure is not significant for the introduction of product innovations in high-tech industries (see estimates $a$ and $c$ in Table 10). Results for development are different as this type of expenditure has a significant and (quite similar) positive effect on product innovation across the industries considered. Secondly, regarding process innovations, we find that both research and development have a greater effect in low-tech industries (see estimates $b$ and $c$ in Table 10).

Finally, Table 11 presents the results for innovative sales with industry interactions. We find that the effect of research is shown to be much greater in low-tech industries. However, the effect of development is greater for high-tech industries. Quantile regression allows us to qualify this last result by showing that it happens only for firms in the $90^{\text {th }}$ percentile but not for those in lower percentiles.

Some of these industry results could be surprising. However, they are consistent with the existing literature. In this sense, several authors had already obtained that R\&D as a whole is more conducive to product and process innovation in low-tech industries (see, for example, Mairesse and Mohnen, 2005 and Hall et al., 2009).

Several (non-competing) hypotheses could be proposed to explain this result. First, in lowtech industries, spending more money on research activities could easily lead to new products and processes. However, the way of performing research and development is more important in high-tech industries (i.e., it is not a matter of "how much" but of "how"). This result could be driven by a lower uncertainty involved in low-tech innovation and a more straightforward relationship between research and innovation. One would wonder why then the investments are lower in the low-tech sector and the reason should be that the opportunity costs are also lower. That is, it is easier to survive in the market without $R \& D$ 
investments, partly because of the existence of non-R\&D based alternatives for innovation in low-tech industries, which are less frequently found in high-tech industries (Santamaria et al., 2009), and partly because it is easier to survive with unchanged products and processes in these industries.

Second, this result would mean that opportunities, defined as likelihood of innovation per dollar (see Malerba and Orsenigo, 1993), would not be lower in low-tech industries. This apparent contradiction exists because technological opportunities have been increasingly identified with opportunities coming from new science. However, in their original formulation, the sources of technological opportunities were varied and came also from technological advances by other firms or by a firm's own advances (Dosi, 1988). Innovation in low-tech industries is highly dependent on innovation of other industries (see, for example, Robertson and Patel, 2007), and is based on the recombination of existing knowledge (see, for example, Hirsch-Kreinsen, 2009). This process of recombination demands new roles for applied research and development: the absorption of external knowledge and the adaptation of it to the specifities of the firm (Cohen and Levinthal, 1989).

Finally, a third explanation is that firms in low-tech industries may also be high-tech and science-based firms (see Kirner et al., 2009). Some authors (see, for example, Klevorick et al., 1995) have pointed out that the difference between low and high-tech industries did not depend on science but on the number of scientific fields they depend upon. Therefore, differences among industries in relation to the scientific contents are questionable. 
Table 9. The differentiated effect of Research and Development on patent application

Industry interactions: OECD classification

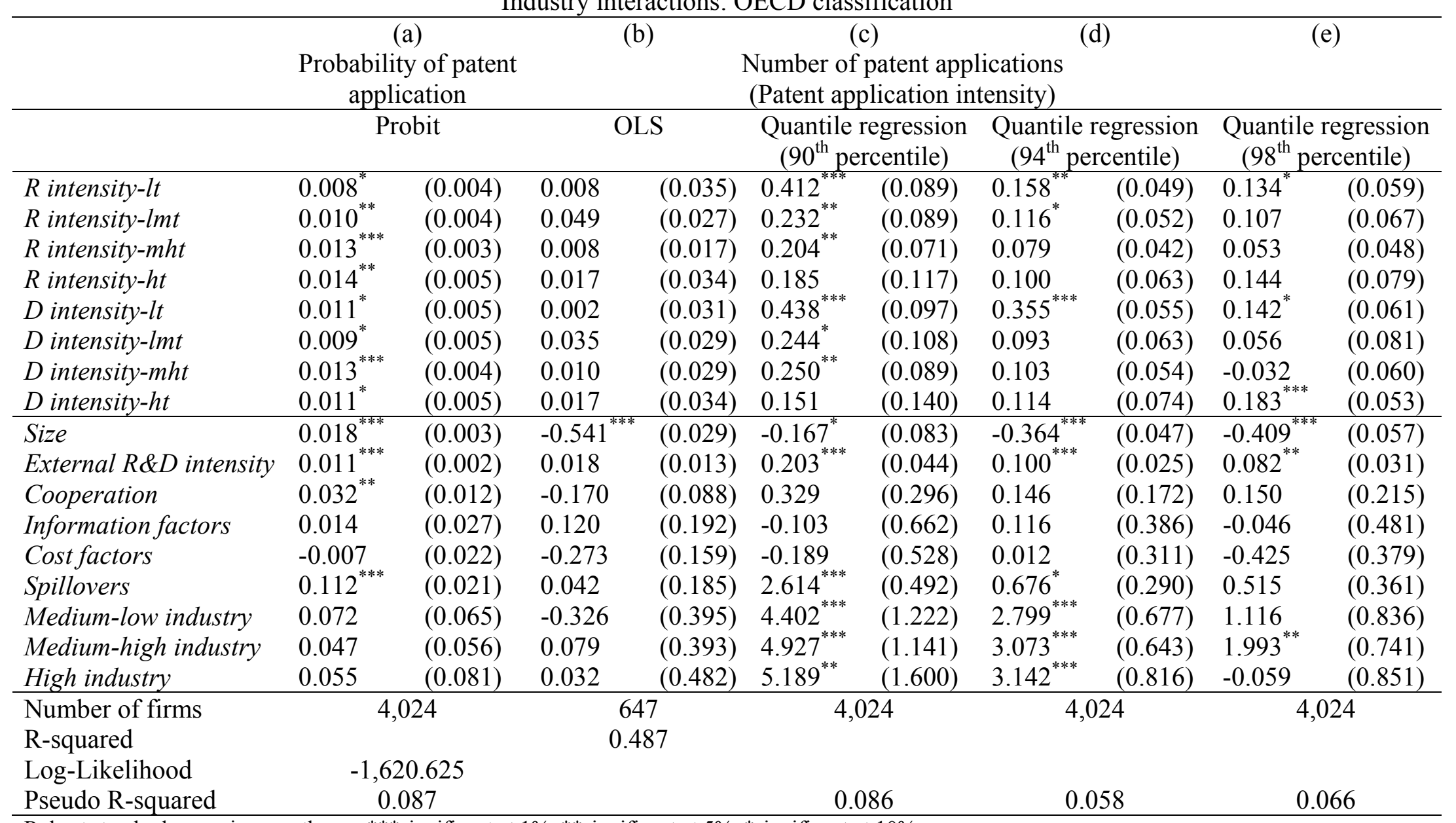

Robust standard errors in parentheses. $* * *$ significant at $1 \%, * *$ significant at $5 \%$, *significant at $10 \%$.

Estimate (a) shows the marginal effects of the independent variables. 
Table 10. The differentiated effect of Research and Development on technological innovation

Industry interactions: OECD classification

\begin{tabular}{|c|c|c|c|c|c|c|c|c|}
\hline & \multirow{2}{*}{\multicolumn{2}{|c|}{$\begin{array}{c}\text { (a) } \\
\text { Product } \\
\text { innovation }\end{array}$}} & \multirow{2}{*}{\multicolumn{2}{|c|}{$\begin{array}{c}\text { (b) } \\
\text { Process } \\
\text { innovation }\end{array}$}} & \multicolumn{4}{|c|}{ (c) } \\
\hline & & & & & \multicolumn{2}{|c|}{$\begin{array}{l}\text { Product } \\
\text { innovation }\end{array}$} & \multicolumn{2}{|c|}{$\begin{array}{l}\text { Process } \\
\text { innovation }\end{array}$} \\
\hline & \multicolumn{2}{|c|}{ Probit } & \multicolumn{2}{|c|}{ Probit } & \multicolumn{4}{|c|}{ Bivariate Probit } \\
\hline$R$ intensity-lt & $0.022^{* * *}$ & $(0.005)$ & $0.018^{* * *}$ & $(0.005)$ & $0.022^{* * *}$ & $(0.005)$ & $0.018^{* * *}$ & $(0.005)$ \\
\hline$R$ intensity-lmt & $0.016^{* *}$ & $(0.005)$ & $0.009^{*}$ & $(0.005)$ & $0.016^{* *}$ & $(0.005)$ & $0.010^{*}$ & $(0.005)$ \\
\hline$R$ intensity-mht & $0.020^{* * *}$ & $(0.004)$ & $0.017^{* * *}$ & $(0.004)$ & $0.020^{* * *}$ & $(0.004)$ & $0.017^{* * *}$ & $(0.004)$ \\
\hline$R$ intensity-ht & 0.005 & $(0.007)$ & 0.006 & $(0.006)$ & 0.005 & $(0.007)$ & 0.007 & $(0.006)$ \\
\hline$D$ intensity-lt & $0.024^{* * *}$ & $(0.006)$ & $0.024^{* * *}$ & $(0.005)$ & $0.024^{* * *}$ & $(0.006)$ & $0.024^{* * *}$ & $(0.005)$ \\
\hline$D$ intensity-lmt & $0.020^{* *}$ & $(0.007)$ & $0.014^{*}$ & $(0.006)$ & $0.021^{* *}$ & $(0.007)$ & $0.014^{*}$ & $(0.006)$ \\
\hline$D$ intensity-mht & $0.031^{* * *}$ & $(0.005)$ & -0.001 & $(0.005)$ & $0.031^{* * *}$ & $(0.005)$ & -0.001 & $(0.005)$ \\
\hline$D$ intensity-ht & $0.029^{* * *}$ & $(0.008)$ & 0.007 & $(0.008)$ & $0.029^{* * *}$ & $(0.008)$ & 0.007 & $(0.008)$ \\
\hline Size & $0.030^{* * *}$ & $(0.005)$ & $0.051^{* * *}$ & $(0.005)$ & $0.031^{* * *}$ & $(0.005)$ & $0.051^{* * *}$ & $(0.005)$ \\
\hline External $R \& D$ intensity & $0.009^{* * *}$ & $(0.003)$ & 0.004 & $(0.002)$ & $0.009^{* * *}$ & $(0.003)$ & 0.004 & $(0.002)$ \\
\hline Cooperation & $0.076^{* * *}$ & $(0.018)$ & $0.055^{* * *}$ & $(0.016)$ & $0.076^{* * *}$ & $(0.018)$ & $0.055^{* * *}$ & $(0.016)$ \\
\hline Information factors & 0.001 & $(0.038)$ & 0.036 & $(0.035)$ & 0.001 & $(0.038)$ & 0.036 & $(0.035)$ \\
\hline Cost factors & -0.046 & $(0.031)$ & 0.023 & $(0.029)$ & -0.047 & $(0.031)$ & 0.023 & $(0.029)$ \\
\hline Spillovers & $0.127^{* * *}$ & $(0.031)$ & $0.078^{* *}$ & $(0.029)$ & $0.127^{* * *}$ & $(0.031)$ & $0.078^{* *}$ & $(0.029)$ \\
\hline Medium-low industry & 0.054 & $(0.072)$ & 0.097 & $(0.058)$ & 0.056 & $(0.072)$ & 0.095 & $(0.058)$ \\
\hline Medium-high industry & 0.037 & $(0.067)$ & 0.060 & $(0.057)$ & 0.039 & $(0.067)$ & 0.059 & $(0.058)$ \\
\hline High industry & 0.145 & $(0.095)$ & 0.064 & $(0.078)$ & 0.148 & $(0.095)$ & 0.062 & $(0.078)$ \\
\hline Number of firms & \multicolumn{2}{|c|}{4,024} & \multicolumn{2}{|c|}{4,024} & \multicolumn{4}{|c|}{4,024} \\
\hline Log-Likelihood & \multicolumn{2}{|c|}{$-2,609.017$} & \multicolumn{2}{|c|}{$-2,342.850$} & \multicolumn{4}{|c|}{$-4,924.531$} \\
\hline Pseudo R-squared & \multirow{2}{*}{\multicolumn{2}{|c|}{0.055}} & \multirow{2}{*}{\multicolumn{2}{|c|}{0.055}} & \\
\hline Test $\rho=0^{1}$ & & & & & & & & \\
\hline
\end{tabular}

Robust standard errors in parentheses.

$* * *$ significant at $1 \%, * *$ significant at $5 \%, *$ significant at $10 \%$.

Coefficients are the marginal effect of the independent variable.

${ }^{1} p$-value from a test of $\rho=0$. 
Table 11. The differentiated effect of Research and Development on innovative sales Industry interactions: OECD classification

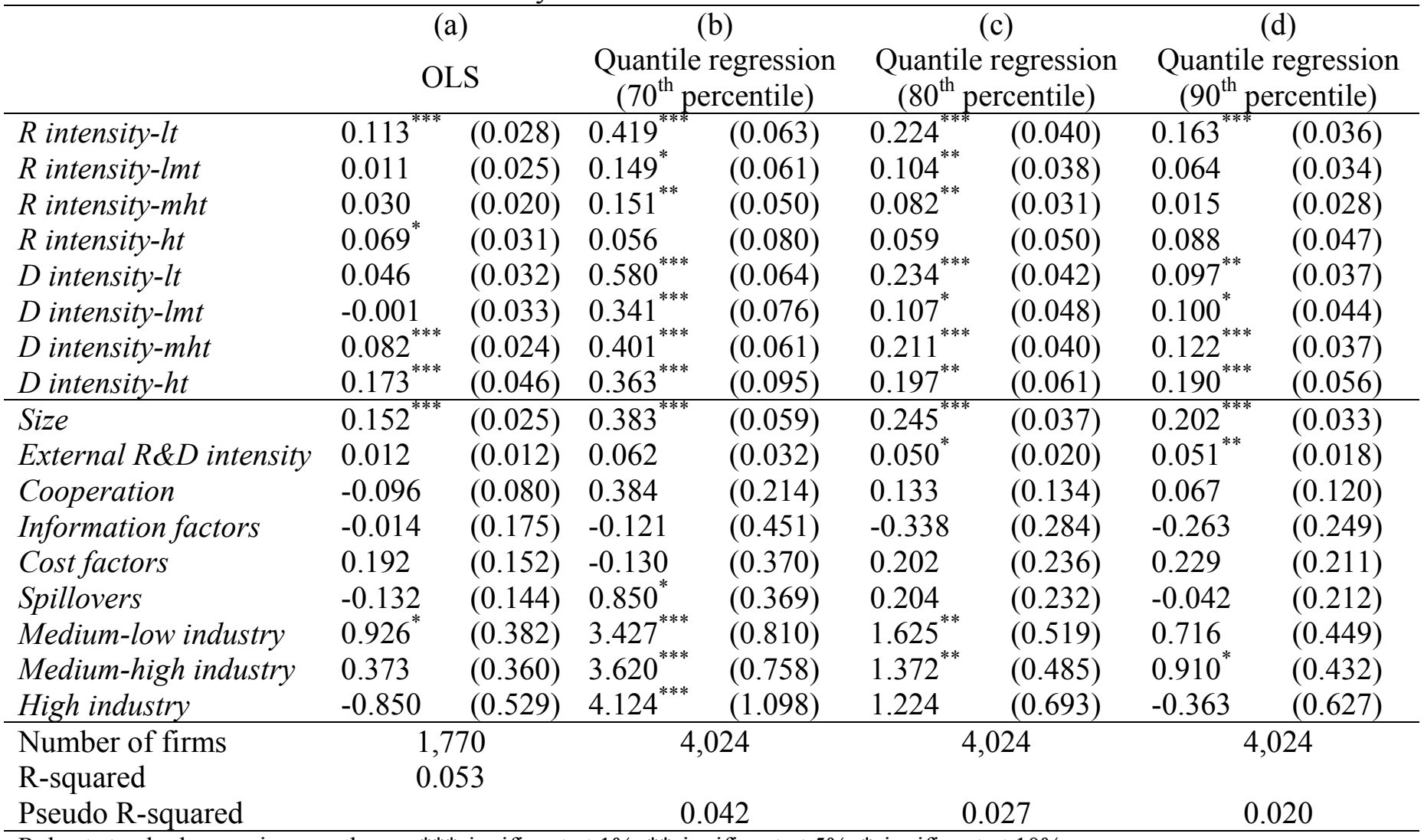

Robust standard errors in parentheses. $* * *$ significant at $1 \%, * *$ significant at $5 \%, *$ significant at $10 \%$.

\subsubsection{Pavitt taxonomy}

At this point, we use Pavitt taxonomy to define the interactions between research and development intensities and industry dummies. Tables A8, A9 and A10 in Appendix B show the results for patent application, technological innovation and innovative sales, respectively.

Results using Pavitt taxonomy confirm both the general and the industry pattern of results. First, research and development have a similar effect on patent application, while the effect of development is greater on product innovations and innovative sales and research has a greater effect on process innovation.

Second, results are consistent with those obtained using the OECD classification, specifically, the importance of research for obtaining sales from new products in supplierdominated (low-tech) industries and the importance of development in science-based (hightech) industries. 


\section{Conclusions}

We obtain new insights on the effect of R\&D on innovation by analyzing the differentiated effect of each activity ( $R$ and $D$ ) on three innovation outputs (patent application, technological innovation and innovative sales). While there is a long tradition of firm-level studies on this topic, research and development had seldom been considered as separate activities. However, as pointed out by the early works by Mansfield (1981) and Link (1982), research and development have important differences, and it is worthy of exploring both the determinants and the effects of this heterogeneity.

We find that both research and development are important for obtaining the innovation outputs analyzed. Firstly, their impact is very similar when patent applications are analyzed. Secondly, development activities seem to have a greater effect on product innovation, while research activities seem to have a greater effect on process innovation. Finally and more remarkably, development activities show a much greater effect (between $70 \%-100 \%$ higher, depending on the level of innovation intensity) on sales from new-tothe-market products.

We find evidence supporting the existence of differences between R and D by the sector's technological intensity. In this sense, we find that research activities (and to a lesser extent development activities) have a greater effect on sales from new products and on process innovation in low-tech sectors. We propose several hypotheses than can explain this result, which is consistent with previous studies using $R \& D$ as a whole. Moreover, we find that both activities have a greater effect on patent applications for firms belonging to high-tech sectors. In this sense, our results are consistent with the existing literature focused on patents as a measure of innovation results.

To summarize, three main conclusions can be advanced. Firstly, we find that Spanish firms devote a large portion of $R \& D$ expenditures to research activities, compared to other developed countries. However, development expenditures show a much greater effect on sales from new products than research expenditures. To some extent, this result resembles the European paradox, but at the firm level. If increasing the economic returns of R\&D through sales from new products is a central interest to policy makers, public support programs should make an effort to foster development activities, as these activities are 
more connected to the market. It is worth noting that development activities still involve spillovers (especially market spillovers) so that the classical justification for public intervention applies. However, evidence on additionality of public funding for R and D is not conclusive. For example, Link (1982) finds a higher additionality for development, while Aerts and Thorwall (2009) and Clausen (2009) find a higher additionality for research.

Secondly, our results do not mean that research is not important. On the contrary, its effect is significantly positive for obtaining sales from new-to-the-market products. Moreover, research activities are very important in obtaining product innovations, which help to increase productivity levels of firms, a very important target of policy initiatives.

Thirdly, we have obtained that research and development activities have a great effect on innovation in low-tech sectors. This result could lead to a rethinking of innovation policies, which are mainly focused on high-tech sectors and also to a rethinking of some widely used concepts, such as science-based sectors, technological opportunity and industry classifications.

Finally, further research is needed. It is likely that research and development have different time lags in their conversion to innovation results, the influence of development being more visible in the short term. Moreover, it is important to test whether research and development are complementary in obtaining innovation results. Finally, we analyze the Spanish case, where a low degree of R\&D intensity is combined with relative orientation to research. Evidence from other countries on the differentiated effect of $\mathrm{R}$ and $\mathrm{D}$ on innovation results might be revealing ${ }^{17}$.

\footnotetext{
${ }^{17}$ Although previous research using CIS data finds that results for Spain do not seem to be strikingly different from the results for other European countries (see Griffith et al., 2006, for evidence on the relationship between innovation and productivity, and Abramovsky et al., 2009, for evidence on the determinants of co-operative innovative activity).
} 


\section{References}

Abramovsky, L., Kremp, E., López, A., Schmidt, T. and Simpson, H. (2009). Understanding co-operative innovative activity: Evidence from four European countries, Economics of Innovation and New Technology, 18(3), 243-265.

Acs, Z.; Audretsch, D. and Feldman, M. (1992). Real effects of academic research: comment, American Economic Review, 82(1), 363-367.

Aerts, K. and Thorwarth, S. (2009). Additionality effects of public R\&D funding: "R" vs. “D”, FBE Research Report MSI_0811, K.U.Leuven.

Amsdem, A. H. and Tschang, F.T. (2003). A new approach to assessing the technological complexity of different categories of R\&D (with examples from Singapore), Research Policy, 32, 553-572.

Angrist, JD. and Pischke, JD. (2008). Mostly Harmless Econometrics. An Empiricist's Companion. Princeton University Press.

Arnold, E. (2004). Evaluating research and innovation policy: a systems world needs systems evaluations, Research Evaluation, 131, 3-17.

Asheim, B.T. and Coenen, L. (2005). Knowledge bases and regional innovation systems: Comparing Nordic clusters, Research Policy, 34, 1173-1190.

Balconi, M., Brusoni, S. and Orsenigo, L. (2010). In defence of the linear model: An essay, Research Policy, 39, 1-13.

Banal-Estañol, A. and Macho-Stadler, I. (2010). Scientific and Commercial Incentives in R\&D: Research versus Development?, Journal of Economics \& Management Strategy, 19(1), 185-221.

Barge-Gil, A., Nieto, MJ. and Santamaría, L. (2011). Hidden innovators: the role of non R\&D activities, Technology Analysis \& Strategic Management 23(4), 415-432.

Bercovitz, J.E.L. and Feldman, M. P. (2007). Fishing upstream: Firm innovation strategy and university alliances, Research Policy, 36, 930-948.

Bertrand, O. (2009). Effects of foreign acquisitions on R\&D activity: Evidence from firmlevel data in France, Research Policy, 38, 1021-1031.

Clausen, T.H. (2009). Do subsidies have positive impacts on R\&D and innovation activities at the firm level, Structural Change and Economic Dynamics, 20, 239-253.

Cohen, W. and Levinthal, D. (1989). Innovation and learning: The two faces of R\&D, Economic Journal, 99, 569-596. 
Conte, A. (2009). Mapping innovative activity using microdata, Applied Economic Letters, $16,1795-1799$.

Chiesa, V. (2001). R\&D strategy and organisation. Managing technical change in dynamic contexts. London. Imperial College Press.

Chiesa, V. and Frattini, F. (2007). Exploring the differences in performance measurement between research and development: evidence from a multiple case study, $R \& D$ Management, 37(4), 283-301.

Crepon, B., Duguet, E. and Mairesse, J. (1998). Research, innovation and productivity: An econometric analysis at the firm level, Economics of Innovation and New Technology, 7, 115-158.

Crepon, B. and Mairesse, J. (1993). Recherche et développement, qualification et productivité des enterprises, in D. Guellec (ed.), Innovations et compétivité, INSEEMéthodes no. 37-38, Paris.

Cuneo, P. and Mairesse, J. (1984). Productivity and R\&D at the firm level in French manufacturing, in Z. Griliches (eds), R\&D, patents and productivity. Chicago. IL: University of Chicago Press, 375-392.

Czarnitzki, D., Kraft, K. and Thorwarth, S. (2009). The knowledge production of "R" and “D”, Economic Letters, 105, 141-143.

Czarnitzki, D., Hottenrott, H. and Thorwarth, S. (2011). Industrial research versus development investment: the implications of financial constraints, Cambridge Journal of Economics, forthcoming.

Czarnitzki, D. and Thorwarth, S. (2010). Productivity effects of basic research in low-tech and high-tech industries. Mimeo.

Dosi, G. (1988). Sources, procedures and microeconomic effects of innovation. Journal of Economic Literature. 26 (3), 1120-1171.

Griffith, R., Huergo, E., Mairesse, J. and Peters, B. (2006). Innovation and productivity across four European countries, Oxford Review of Economic Policy, 22(4), 483-498.

Griliches, Z., (1995). R\&D and productivity: Econometric results and measurement issues, in Handbook of the economics of innovation and technological change, ed. P. Stoneman. Oxford, U.K., and Cambridge, Mass.: Basil Blackwell, 52-89.

Hall, B.H., (1996). The private and social returns to research and development, in Technology, R\&D, and the economy, ed. B. Smith and C. Barfield. Washington, D.C.: Brookings Institution and American Enterprise Institute. 140-162. 
Hall, B.H., Lotti, F. and Mairesse, J. (2009). Innovation and productivity in SMEs: empirical evidence from Italy, Small Business Economics, 33, 13-33.

Hall, B.H., Mairesse, J. and Mohnen, P. (2010). Measuring the returns to R\&D, in Hall, B.H., Rosenberg, N. (Eds.): Handbook of the Economics of Innovation.

Hirsch-Kreinsen, H. (2009). "Low-Tech" Innovations, Industry and Innovation, 15(1), 1943.

Jaffe, A. (1989). Real effects of academic research, American Economic Review, 79(5), 957-970.

Karlsson, M., Trygg, L. and Elfström, B-O. (2004). Measuring R\&D productivity: complementing the picture by focusing on research activities, Technovation, 24, 179-186.

Kirner, E., Kinkel, S. and Jaeger, A. (2009). Innovation paths and the innovation performance of low-technology firms-An empirical analysis of German industry, Research Policy, 38, 447-458.

Klevorick, A., Levin, R., Nelson, R. and Winter, S. (1995). On the sources and significance of inter-industry differences in technological opportunities, Research Policy, 24, 185-205.

Laestadius, S., 1998. Technology level, knowledge formation and industrial competence in paper manufacturing, in: Eliasson, G., et al. (Eds.), Micro Foundations of Economic Growth. The University of Michigan Press, Ann Arbour, pp. 212-226.

Leifer, R. and Triscari, T. (1987). Research versus Development: Differences and similarities, IEEE Transactions on Engineering Management, 34(2), 71-78.

Link, A. N. (1982). An analysis of the composition of R\&D spending, Southern Economic Journal, 49(2), 342-349.

Link, A.N. (1985). The changing composition of R\&D, Managerial and Decision Economics, 6(2), 125-128.

Mairesse, J. and Mohnen, P. (1995). Research \& development and productivity: A survey of the econometric literature, CIRANO, December. Mimeo.

Mairesse, J. and Mohnen, P. (2005). The importance of R\&D for innovation: A reassessment using French survey data, Journal of Technology Transfer, 30 (1/2), 183-197.

Mairesse, J. and Mohnen, P. (2010). Using innovation surveys for econometric analysis, in Hall, B.H., Rosenberg, N. (Eds.), Handbook of the Economics of Innovation.

Mairesse, J. and Sassenou, M. (1991). R\&D and productivity: A survey of econometric studies at the firm level, STI Review, 8, 9-43. 
Malerba, F. and Orsenigo, L. (1993). Technological regimes and firm behaviour, Industrial and Corporate Change, 2(1), 45-70.

Malerba, F. (2007). Innovation and the dynamics and evolution of industries: Progress and challenges, International Journal of Industrial Organization, 25, 675-699.

Mansfield, E. (1981). Composition of R and D expenditures: Relationship to size of firm, concentration and innovative output, Review of Economics and Statistics, 63(4), 610-615.

Martinez-Ros, E. (2000). Explaining the decisions to carry out product and process innovations: the Spanish case, The Journal of High Technology Management Research, $10(2), 223-242$.

Moodyson, J., Coenen, L. and Asheim, B. (2008). Explaining spatial patterns of innovation: analytical and synthetic modes of knowledge creation in the Medicon Valley life-science cluster, Environment and Planning, 40, 1040-1056.

Nadiri, M. I., (1993). Innovations and technological spillovers, NBER Working Paper no. 4423. Cambridge, Mass.: National Bureau of Economic Research.

Nelson, R.R. (1959). The simple economics of basic research, Journal of Political Economy, 32, 297-306.

OECD (2005), Oslo Manual. Guidelines for collecting and interpreting innovation-3rd Edition. OECD Publications: Paris.

Pavitt, K. (1984). Sectoral patterns of technical change: towards a taxonomy and a theory, Research Policy, 13, 343-373

Rammer, C., Czarnitzki, D. and Spielkamp A. (2009). Innovation success of non-R\&Dperformers: substituting technology by management in SMEs, Small Business Economics, $33,35-58$.

Reichstein, T. and Salter, A. (2006). Investigating the sources of process innovation among UK manufacturing firms, Industrial and Corporate Change, 15(4), 653-682.

Robertson, P. and Patel, P. (2007). New wine in old bottles: technological diffusion in developed economies, Research Policy, 36, 708-721.

Rouvinen, P. (2002). Characteristics of product and process innovators: some evidence from the Finnish innovation survey, Applied Economic Letters, 9, 575-580.

Salter, A. and Martin, B. (2001). The economic benefits of publicly funded basic research: a critical review, Research Policy, 30, 509-524. 
Santamaría, L., Nieto, MJ. and Barge-Gil, A. (2009). Beyond formal R\&D: Taking advantage of other sources of innovation in low-and medium-technology industries, Research Policy, 38, 507-517.

Sirilli, G. and Evangelista, G. (1998). Technological innovation in services and manufacturing: Results from Italian surveys, Research Policy, 27(9), 881 -899.

Van Ark, Dougherty, S., Inklaar, R. and McGuckin, R. (2008). The structure and location of business R\&D: recent trends and measurement implications, International Journal of Foresight and Innovation Policy, 4(1/2), 8-28.

Van Beers, C., Kleinknecht, A., Ortt, R. and Verburg, R. (2008). Determinants of innovative behavior. A firm's internal practices and its external environment. Palgrave. New York.

Wieser, R. (2005). Research and development, productivity and spillovers: Empirical evidence at the firm level, Journal of Economic Surveys, 19(4), 587-621.

Wooldridge, J. (2002). Econometric Analysis of Cross Section and Panel Data. MIT Press. 


\section{Appendix A: Variable definitions}

Cost factors: Sum of the scores of importance of the following obstacles to the innovation process (number between 1 (high) and 4 (factor not experienced)): Lack of funds within the enterprise or group; Lack of finance from sources outside the enterprise; Innovation costs too high. Rescaled between 0 (factor not experienced) and 1 (high).

Development intensity: Ratio between intramural development expenditures and total number of employees (in logs).

External $R \& D$ intensity: Ratio between external $\mathrm{R} \& \mathrm{D}$ expenditures and total number of employees (in logs).

High-tech industry: Dummy variable that takes the value one if the firm belongs to the following industries: aircraft, spacecraft, pharmaceuticals, office machinery, radio and TV equipment, and medical and optical instruments.

Information factors: Sum of the scores of importance of the following obstacles to the innovation process (number between 1 (high) and 4 (factor not experienced)): Lack of qualified personnel; Lack of information on technology; Lack of information on markets; Difficulty in finding cooperation partners for innovation. Rescaled between 0 (factor not experienced) and 1 (high).

Innovative sales intensity: Ratio between sales due to new-to-the-market-products and total number of employees (in logs).

Low-medium tech industry: Dummy variable that takes the value one if the firm belongs to the following industries: petroleum refining, rubber and plastic products, non-metallic mineral products, ferrous metals, non-ferrous metals, shipbuilding and other manufacturing.

Low-tech industry: Dummy variable that takes the value one if the firm belongs to the following industries: food, beverages, tobacco, textile and clothing, wood products, paper, printing, furniture, games and toys, and recycling.

Medium-high tech industry: Dummy variable that takes the value one if the firm belongs to the following industries: chemicals, non-electrical machinery, electrical machinery, motor vehicles and other transport equipment.

Patent application: Dummy variable that takes the value one if the firm has applied for patents.

Patent application intensity: Number of patent applications per 100,000 employees (in $\operatorname{logs})$.

Process innovation: Dummy variable that takes the value one if the firm reports having introduced process innovations. 
Product innovation: Dummy variable that takes the value one if the firm reports having introduced a new good or service into its market before its competitors.

Research intensity: Ratio between intramural research expenditures and total number of employees (in logs).

Scale-Intensive industry: Dummy variable that takes the value one if the firm belongs to the following industries: food, beverages, tobacco, printing, petroleum refining, non-metallic mineral products, ferrous metals, non-ferrous metals, shipbuilding, motor vehicles and other transport equipment.

Science-Based industry: Dummy variable that takes the value one if the firm belongs to the following industries: chemicals, pharmaceuticals, radio and TV equipment, aircraft and spacecraft.

Size: Total turnover (in logs).

Specialized-Suppliers industry: Dummy variable that takes the value one if the firm belongs to the following industries: non-electrical machinery, electrical machinery, office machinery, and medical and optical instruments.

Spillovers: Sum of the scores of importance of the following information sources for the innovation process (number between 1 (high) and 4 (not used)): Conferences, trade fairs and exhibitions; Scientific journals and trade/technical publications and professional and industry associations. Rescaled between 0 (not used) and 1 (high).

Supplier-Dominated industry: Dummy variable that takes the value one if the firm belongs to the following industries: textile and clothing, wood products, paper, rubber and plastic products, furniture, games and toys, recycling and other manufacturing. 


\section{Appendix B: Additional results}

Table A1. The differentiated effect of Research and Development on patent application Robustness check 1: intensities for the period 2005-2006

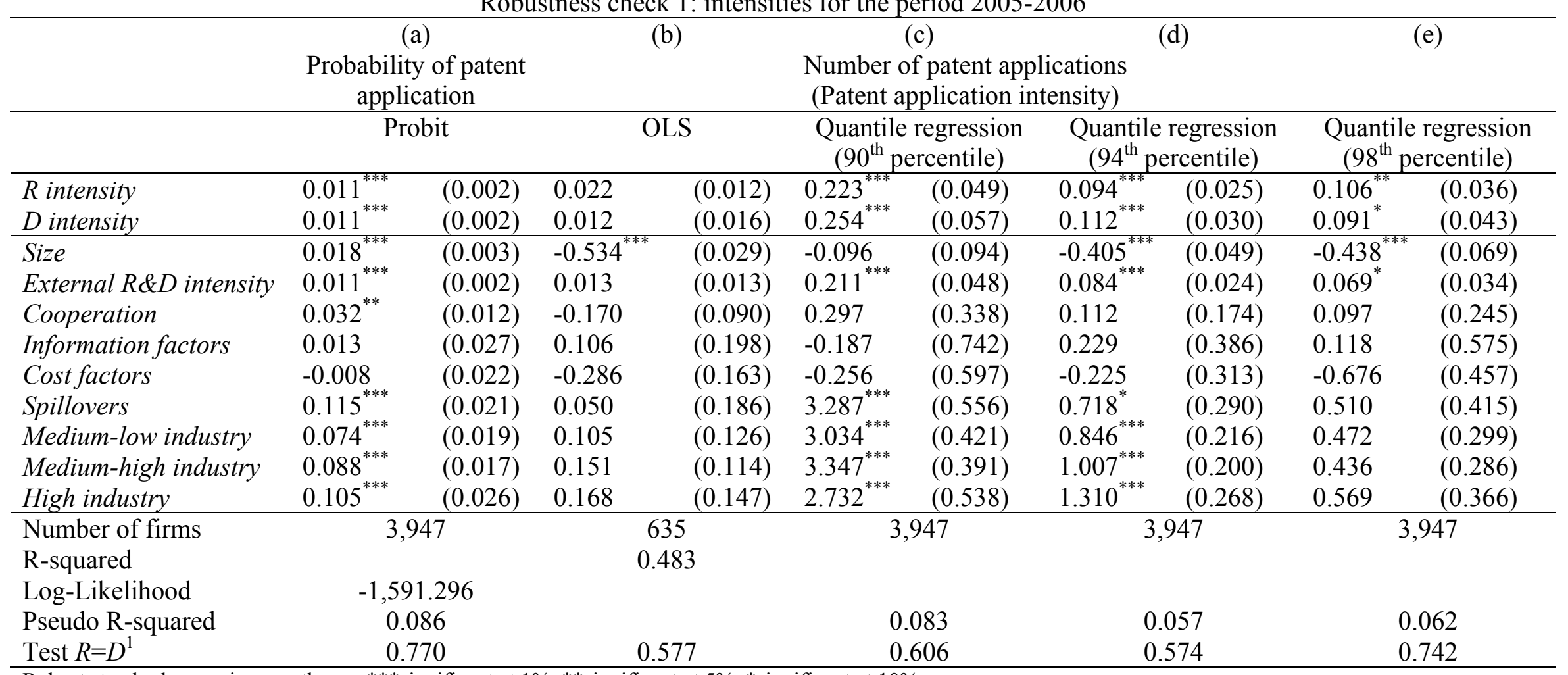

Robust standard errors in parentheses. $* * *$ significant at $1 \%,{ }^{*}$ significant at $5 \%$, ${ }^{*}$ significant at $10 \%$.

Estimate (a) shows the marginal effects of the independent variables.

${ }^{1} p$-value from a test of equality of estimated coefficients of $R$ intensity and $D$ intensity. 
Table A2. The differentiated effect of Research and Development on technological innovation

Robustness check 1: intensities for the period 2005-2006

\begin{tabular}{|c|c|c|c|c|c|c|c|c|}
\hline & \multirow{2}{*}{\multicolumn{2}{|c|}{$\begin{array}{c}\text { (a) } \\
\text { Product } \\
\text { innovation }\end{array}$}} & \multirow{2}{*}{\multicolumn{2}{|c|}{$\begin{array}{c}\text { (b) } \\
\text { Process } \\
\text { innovation }\end{array}$}} & \multicolumn{4}{|c|}{ (c) } \\
\hline & & & & & \multicolumn{2}{|c|}{$\begin{array}{c}\text { Product } \\
\text { innovation }\end{array}$} & \multicolumn{2}{|c|}{$\begin{array}{c}\text { Process } \\
\text { innovation }\end{array}$} \\
\hline & \multicolumn{2}{|c|}{ Probit } & \multicolumn{2}{|c|}{ Probit } & \multicolumn{4}{|c|}{ Bivariate Probit } \\
\hline$R$ intensity & $0.014^{* * *}$ & $(0.003)$ & $0.011^{* * *}$ & $(0.002)$ & $0.014^{* * *}$ & $(0.003)$ & $0.011^{* * *}$ & $(0.002)$ \\
\hline$D$ intensity & $0.020^{* * *}$ & $(0.003)$ & $0.007^{* *}$ & $(0.003)$ & $0.020^{* * *}$ & $(0.003)$ & $0.007^{* *}$ & $(0.003)$ \\
\hline Size & $0.030^{* * * *}$ & $(0.005)$ & $0.047^{* * *}$ & $(0.005)$ & $0.031^{* * * *}$ & $(0.005)$ & $0.048^{* * *}$ & $(0.005)$ \\
\hline External R\&D intensity & $0.009^{* * *}$ & $(0.002)$ & $0.005^{*}$ & $(0.002)$ & $0.009^{* * *}$ & $(0.002)$ & $0.005^{*}$ & $(0.002)$ \\
\hline Cooperation & $0.079^{* * *}$ & $(0.018)$ & $0.059^{* * *}$ & $(0.016)$ & $0.080^{* * *}$ & $(0.018)$ & $0.059^{* * *}$ & $(0.016)$ \\
\hline Information factors & -0.010 & $(0.038)$ & 0.032 & $(0.035)$ & -0.010 & $(0.038)$ & 0.033 & $(0.035)$ \\
\hline Cost factors & -0.031 & $(0.032)$ & 0.030 & $(0.029)$ & -0.031 & $(0.032)$ & 0.030 & $(0.029)$ \\
\hline Spillovers & $0.133^{* * *}$ & $(0.031)$ & $0.093^{* *}$ & $(0.029)$ & $0.133^{* * *}$ & $(0.031)$ & $0.093^{* *}$ & $(0.029)$ \\
\hline Medium-low industry & 0.003 & $(0.023)$ & 0.011 & $(0.021)$ & 0.003 & $(0.023)$ & 0.011 & $(0.021)$ \\
\hline Medium-high industry & $0.080^{* * *}$ & $(0.021)$ & $-0.077^{* * *}$ & $(0.019)$ & $0.081^{* * *}$ & $(0.021)$ & $-0.078^{* * *}$ & $(0.019)$ \\
\hline High industry & $0.087^{* *}$ & $(0.029)$ & $-0.083^{* *}$ & $(0.028)$ & $0.088^{* *}$ & $(0.029)$ & $-0.084^{* *}$ & $(0.028)$ \\
\hline Number of firms & \multicolumn{2}{|c|}{3,947} & \multicolumn{2}{|c|}{3,947} & \multicolumn{4}{|c|}{3,947} \\
\hline Log-Likelihood & \multicolumn{2}{|c|}{$-2,577.960$} & \multicolumn{2}{|c|}{$-2,319.980$} & \multicolumn{4}{|c|}{$-4,868.121$} \\
\hline Pseudo R-squared & \multirow{2}{*}{\multicolumn{2}{|c|}{0.048}} & \multicolumn{2}{|c|}{0.047} & \multirow{2}{*}{\multicolumn{4}{|c|}{0.000}} \\
\hline Test $\rho=0^{1}$ & & & & & & & & \\
\hline Test $R=D^{2}$ & \multicolumn{2}{|c|}{0.065} & \multicolumn{2}{|c|}{0.152} & \multicolumn{2}{|c|}{0.062} & \multicolumn{2}{|c|}{0.147} \\
\hline
\end{tabular}


Table A3. The differentiated effect of Research and Development on innovative sales Robustness check 1: intensities for the period 2005-2006

\begin{tabular}{|c|c|c|c|c|c|c|c|c|}
\hline \multirow[b]{2}{*}{$R$ intensity } & \multicolumn{2}{|c|}{ OLS } & \multicolumn{2}{|c|}{$\begin{array}{l}\text { Quantile regression } \\
\left(70^{\text {th }} \text { percentile }\right)\end{array}$} & \multicolumn{2}{|c|}{$\begin{array}{l}\text { Quantile regression } \\
\left(80^{\text {th }} \text { percentile }\right)\end{array}$} & \multicolumn{2}{|c|}{$\begin{array}{l}\text { Quantile regression } \\
\left(90^{\text {th }} \text { percentile }\right)\end{array}$} \\
\hline & $0.042^{* * *}$ & $(0.012)$ & $0.140^{* * *}$ & $(0.025)$ & $0.088^{* * *}$ & $(0.018)$ & $0.058^{* * *}$ & $(0.017)$ \\
\hline D intensity & $0.058^{* * *}$ & $(0.015)$ & $0.282^{* * *}$ & $(0.029)$ & $0.142^{* * *}$ & $(0.021)$ & $0.105^{* * *}$ & $(0.019)$ \\
\hline Size & $0.141^{* * *}$ & $(0.025)$ & $0.337^{* * *}$ & $(0.049)$ & $0.196^{* * *}$ & $(0.036)$ & $0.192^{* * *}$ & $(0.032)$ \\
\hline External $R \& D$ intensity & 0.012 & $(0.011)$ & $0.085^{* * *}$ & $(0.025)$ & $0.065^{* * *}$ & $(0.018)$ & $0.049^{* *}$ & $(0.016)$ \\
\hline Cooperation & -0.083 & $(0.081)$ & $0.387^{*}$ & $(0.177)$ & 0.177 & $(0.129)$ & 0.024 & $(0.117)$ \\
\hline Information factors & -0.038 & $(0.177)$ & -0.458 & $(0.375)$ & -0.413 & $(0.271)$ & -0.235 & $(0.244)$ \\
\hline Cost factors & 0.237 & $(0.155)$ & 0.237 & $(0.307)$ & 0.185 & $(0.224)$ & 0.249 & $(0.205)$ \\
\hline Spillovers & -0.093 & $(0.148)$ & $0.892^{* *}$ & $(0.304)$ & 0.332 & $(0.220)$ & 0.018 & $(0.206)$ \\
\hline Medium-low industry & 0.082 & $(0.115)$ & 0.148 & $(0.221)$ & 0.242 & $(0.159)$ & 0.089 & $(0.144)$ \\
\hline Medium-high industry & 0.142 & $(0.100)$ & $0.895^{* * *}$ & $(0.204)$ & $0.537^{* * *}$ & $(0.147)$ & 0.178 & $(0.133)$ \\
\hline High industry & -0.147 & $(0.136)$ & 0.409 & $(0.281)$ & 0.100 & $(0.202)$ & -0.118 & $(0.181)$ \\
\hline Number of firms & \multicolumn{2}{|c|}{1,741} & \multicolumn{2}{|c|}{3,947} & \multicolumn{2}{|c|}{3,947} & \multicolumn{2}{|c|}{3,947} \\
\hline R-squared & \multirow{2}{*}{\multicolumn{2}{|c|}{0.035}} & \multirow{2}{*}{\multicolumn{2}{|c|}{0.033}} & \multirow{2}{*}{\multicolumn{2}{|c|}{0.022}} & \multirow{2}{*}{\multicolumn{2}{|c|}{0.014}} \\
\hline Pseudo R-squared & & & & & & & & \\
\hline Test $R=D^{1}$ & \multicolumn{2}{|c|}{0.349} & \multicolumn{2}{|c|}{0.000} & \multicolumn{2}{|c|}{0.022} & \multicolumn{2}{|c|}{0.031} \\
\hline
\end{tabular}

Robust standard errors in parentheses. $* * *$ significant at $1 \%, * *$ significant at $5 \%,{ }^{*}$ significant at $10 \%$.

${ }^{1} p$-value from a test of equality of estimated coefficients of $R$ intensity and $D$ intensity. 
Table A4. The differentiated effect of Research and Development on patent application Robustness check 2: continuous R\&D performers

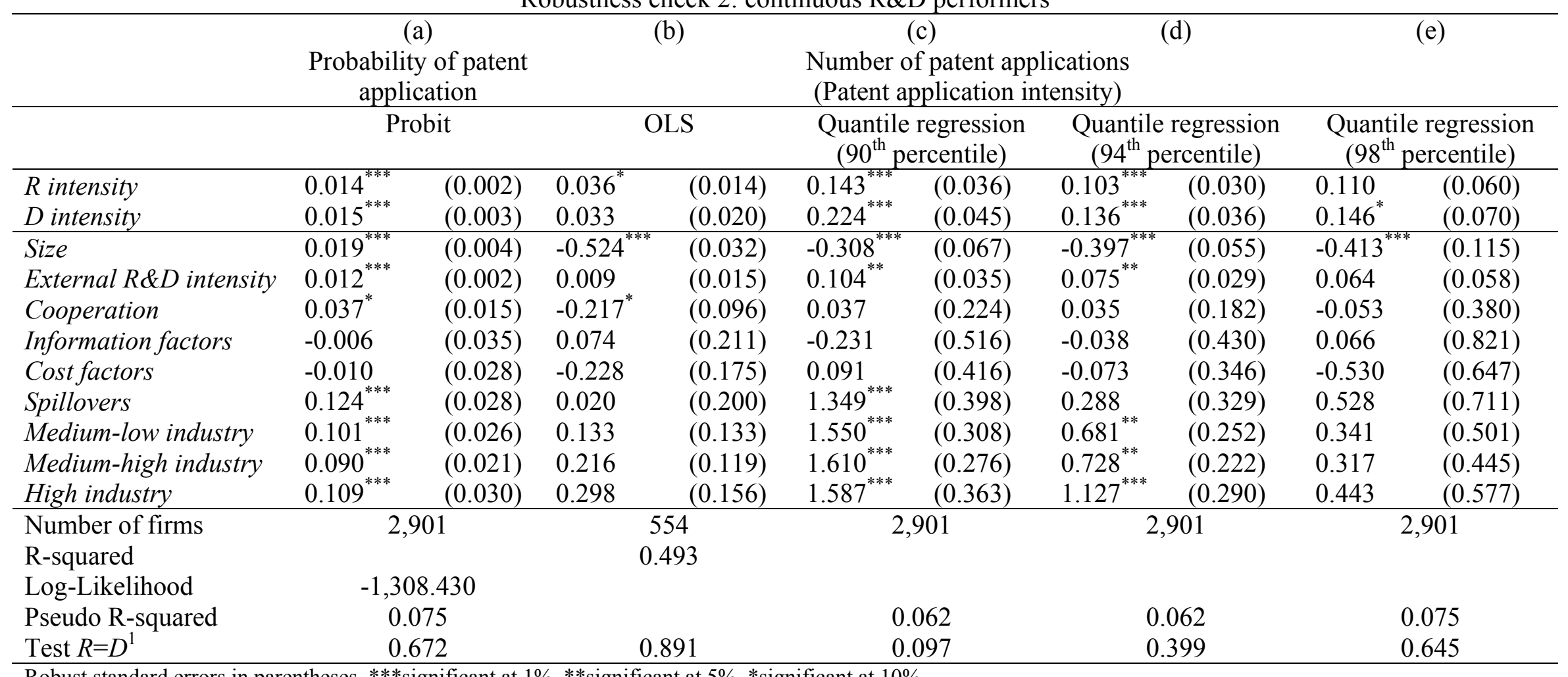

Robust standard errors in parentheses. ***significant at $1 \%, * *$ significant at $5 \%$, *significant at $10 \%$.

Estimate (a) shows the marginal effects of the independent variables.

${ }^{1} p$-value from a test of equality of estimated coefficients of $R$ intensity and $D$ intensity. 
Table A5. The differentiated effect of Research and Development on technological innovation

Robustness check 2: continuous R\&D performers

\begin{tabular}{|c|c|c|c|c|c|c|c|c|}
\hline \multirow[b]{4}{*}{$P$ intority } & \multirow{2}{*}{\multicolumn{2}{|c|}{$\begin{array}{c}\text { (a) } \\
\text { Product } \\
\text { innovation }\end{array}$}} & \multirow{2}{*}{\multicolumn{2}{|c|}{$\begin{array}{c}\text { (b) } \\
\text { Process } \\
\text { innovation }\end{array}$}} & \multicolumn{4}{|c|}{ (c) } \\
\hline & & & & & \multicolumn{2}{|c|}{$\begin{array}{l}\text { Product } \\
\text { innovation }\end{array}$} & \multicolumn{2}{|c|}{$\begin{array}{l}\text { Process } \\
\text { innovation }\end{array}$} \\
\hline & \multicolumn{2}{|c|}{ Probit } & \multicolumn{2}{|c|}{ Probit } & \multicolumn{4}{|c|}{ Bivariate Probit } \\
\hline & $0.014^{* * *}$ & $(0.003)$ & $0.011^{* * *}$ & $(0.003)$ & $0.014^{* * *}$ & $(0.003)$ & $0.011^{* * * *}$ & $(0.003)$ \\
\hline$D$ intensity & $0.026^{* * *}$ & $(0.004)$ & $0.007^{*}$ & $(0.003)$ & $0.026^{* * *}$ & $(0.004)$ & $0.007^{*}$ & $(0.003)$ \\
\hline Size & $0.025^{* * *}$ & $(0.006)$ & $0.041^{* * *}$ & $(0.005)$ & $0.025^{* * *}$ & $(0.006)$ & $0.041^{* * *}$ & $(0.005)$ \\
\hline External R\&D intensity & $0.007^{*}$ & $(0.003)$ & 0.003 & $(0.003)$ & $0.007^{*}$ & $(0.003)$ & 0.002 & $(0.003)$ \\
\hline Cooperation & $0.070^{* * *}$ & $(0.021)$ & $0.066^{* * *}$ & $(0.018)$ & $0.070^{* * *}$ & $(0.021)$ & $0.065^{* * *}$ & $(0.018)$ \\
\hline Information factors & 0.023 & $(0.045)$ & 0.053 & $(0.040)$ & 0.023 & $(0.045)$ & 0.052 & $(0.040)$ \\
\hline Cost factors & $-0.092^{*}$ & $(0.037)$ & 0.018 & $(0.033)$ & $-0.092^{*}$ & $(0.037)$ & 0.018 & $(0.033)$ \\
\hline Spillovers & $0.135^{* * *}$ & $(0.037)$ & $0.086^{* *}$ & $(0.033)$ & $0.135^{* * *}$ & $(0.037)$ & $0.086^{* *}$ & $(0.033)$ \\
\hline Medium-low industry & -0.019 & $(0.028)$ & -0.010 & $(0.026)$ & -0.019 & $(0.028)$ & -0.010 & $(0.026)$ \\
\hline Medium-high industry & 0.029 & $(0.025)$ & $-0.123^{* * *}$ & $(0.023)$ & 0.029 & $(0.025)$ & $-0.123^{* * *}$ & $(0.023)$ \\
\hline High industry & 0.034 & $(0.032)$ & $-0.130^{* * *}$ & $(0.032)$ & 0.035 & $(0.032)$ & $-0.130^{* * *}$ & $(0.032)$ \\
\hline Number of firms & \multicolumn{2}{|c|}{2,901} & \multicolumn{2}{|c|}{2,901} & \multicolumn{4}{|c|}{2,901} \\
\hline Log-Likelihood & \multicolumn{2}{|c|}{$-1,933.122$} & \multicolumn{2}{|c|}{$-1,613.705$} & \multicolumn{4}{|c|}{$-3,536.960$} \\
\hline Pseudo R-squared & \multicolumn{2}{|c|}{0.039} & \multicolumn{2}{|c|}{0.051} & \multirow{2}{*}{\multicolumn{4}{|c|}{0.000}} \\
\hline Test $\rho=0^{1}$ & \multirow{2}{*}{\multicolumn{2}{|c|}{0.002}} & \multirow{2}{*}{\multicolumn{2}{|c|}{0.339}} & & & & \\
\hline Test $R=D^{2}$ & & & & & \multicolumn{2}{|c|}{0.002} & \multicolumn{2}{|c|}{0.325} \\
\hline
\end{tabular}


Table A6. The differentiated effect of Research and Development on innovative sales Robustness check 2: continuous R\&D performers

\begin{tabular}{|c|c|c|c|c|c|c|c|c|}
\hline \multirow[b]{2}{*}{$R$ intensity } & \multicolumn{2}{|c|}{ OLS } & \multicolumn{2}{|c|}{$\begin{array}{l}\text { Quantile regression } \\
\left(70^{\text {th }} \text { percentile }\right)\end{array}$} & \multicolumn{2}{|c|}{$\begin{array}{l}\text { Quantile regression } \\
\left(80^{\text {th }} \text { percentile }\right)\end{array}$} & \multicolumn{2}{|c|}{$\begin{array}{l}\text { Quantile regression } \\
\left(90^{\text {th }} \text { percentile }\right)\end{array}$} \\
\hline & $0.052^{* * *}$ & $(0.014)$ & $0.105^{* * * 3 *}$ & $(0.023)$ & $0.080^{* * * *}$ & $(0.019)$ & $0.055^{* *}$ & $(0.017)$ \\
\hline$D$ intensity & $0.090^{* * * *}$ & $(0.019)$ & $0.283^{* * *}$ & $(0.027)$ & $0.172^{* * *}$ & $(0.023)$ & $0.116^{* * *}$ & $(0.021)$ \\
\hline Size & $0.157^{* * *}$ & $(0.027)$ & $0.250^{* * *}$ & $(0.043)$ & $0.180^{* * * *}$ & $(0.036)$ & $0.211^{* * *}$ & $(0.031)$ \\
\hline External $R \& D$ intensity & 0.005 & $(0.013)$ & 0.036 & $(0.023)$ & $0.044^{*}$ & $(0.019)$ & $0.039^{*}$ & $(0.017)$ \\
\hline Cooperation & -0.120 & $(0.088)$ & 0.087 & $(0.152)$ & -0.001 & $(0.126)$ & 0.058 & $(0.111)$ \\
\hline Information factors & 0.039 & $(0.193)$ & -0.215 & $(0.327)$ & -0.171 & $(0.271)$ & -0.118 & $(0.230)$ \\
\hline Cost factors & 0.234 & $(0.166)$ & -0.085 & $(0.270)$ & -0.066 & $(0.228)$ & 0.241 & $(0.195)$ \\
\hline Spillovers & -0.060 & $(0.163)$ & 0.513 & $(0.271)$ & 0.204 & $(0.222)$ & 0.029 & $(0.200)$ \\
\hline Medium-low industry & 0.019 & $(0.130)$ & 0.011 & $(0.202)$ & -0.020 & $(0.167)$ & -0.009 & $(0.146)$ \\
\hline Medium-high industry & 0.165 & $(0.108)$ & $0.381^{*}$ & $(0.179)$ & 0.214 & $(0.147)$ & 0.001 & $(0.127)$ \\
\hline High industry & -0.173 & $(0.140)$ & -0.011 & $(0.236)$ & -0.186 & $(0.195)$ & -0.308 & $(0.168)$ \\
\hline Number of firms & \multicolumn{2}{|c|}{1,444} & \multicolumn{2}{|c|}{2,901} & \multicolumn{2}{|c|}{2,901} & \multicolumn{2}{|c|}{2,901} \\
\hline R-squared & \multicolumn{2}{|c|}{0.048} & \multirow{2}{*}{\multicolumn{2}{|c|}{0.025}} & \multirow{2}{*}{\multicolumn{2}{|c|}{0.020}} & \multirow{2}{*}{\multicolumn{2}{|c|}{0.017}} \\
\hline Pseudo R-squared & \multirow{2}{*}{\multicolumn{2}{|c|}{0.074}} & & & & & & \\
\hline Test $R=D^{1}$ & & & \multicolumn{2}{|c|}{0.000} & \multicolumn{2}{|c|}{0.000} & \multicolumn{2}{|c|}{0.010} \\
\hline
\end{tabular}

Robust standard errors in parentheses. ${ }^{* * *}$ significant at $1 \%, * *$ significant at $5 \%,{ }^{*}$ significant at $10 \%$.

${ }^{1} p$-value from a test of equality of estimated coefficients of $R$ intensity and $D$ intensity. 
Table A7. Tests of equality of estimated coefficients of $R$ intensity and $D$ intensity (by the firm's industry following the OECE classification)

\begin{tabular}{|c|c|c|c|c|c|c|c|c|}
\hline & $R \_L T$ & $D \_L T$ & $R \_L M T$ & D_LMT & $R \_M H T$ & $D \_M H T$ & $R \_H T$ & $D_{-} H T$ \\
\hline$R \_L T$ & & $\begin{array}{c}0.002(\text { PatInt } 94) \\
0.046 \\
(\text { InnSalInt70) }\end{array}$ & $\begin{array}{c}0.006(\text { InnSalInt }) \\
0.002(\text { InnSalInt } 70) \\
0.031(\text { InnSalInt } 80) \\
0.042(\text { InnSalInt } 90)\end{array}$ & 0.007 (InnSalInt) & $\begin{array}{c}0.014 \text { (InnSalInt) } \\
0.001 \text { (InnSalInt70) } \\
0.005(\text { InnSalInt80) } \\
0.001 \text { (InnSalInt90) }\end{array}$ & 0.005 (InnProc) & $\begin{array}{c}0.048(\text { InnProd }) \\
0.000(\text { InnSalInt } 70) \\
0.010(\text { InnSalInt } 80)\end{array}$ & \\
\hline$D_{-} L T$ & & & $\begin{array}{c}0.002(\text { PatInt } 94) \\
0.037(\text { InnProc }) \\
0.000(\text { InnSalInt } 70) \\
0.021(\text { InnSalInt } 80)\end{array}$ & $\begin{array}{c}0.002 \text { (PatInt94) } \\
0.015 \text { (InnSalInt70) } \\
0.044 \text { (InnSalInt80) }\end{array}$ & $\begin{array}{c}0.000(\text { PatInt } 94) \\
0.000(\text { InnSalInt } 70) \\
0.003(\text { InnSalInt } 80)\end{array}$ & $\begin{array}{c}0.001 \text { (PatInt } 94) \\
0.037 \text { (PatInt98) } \\
0.000(\text { InnProc }) \\
0.040 \text { (InnSalInt70) }\end{array}$ & $\begin{array}{c}0.002 \text { (PatInt94) } \\
0.034 \text { (InnProd }) \\
0.025 \text { (InnProc) } \\
0.000 \text { (InnSalInt } 70) \\
0.007 \text { (InnSalInt80) }\end{array}$ & $\begin{array}{l}0.008 \text { (PatInt } 94) \\
0.023 \text { (InnSalInt) }\end{array}$ \\
\hline$R \_L M T$ & & & & $0.030($ InnSalInt70) & & $\begin{array}{c}0.040(\text { InnSalInt }) \\
0.003(\text { InnSalInt } 70)\end{array}$ & & $0.002($ InnSalInt $)$ \\
\hline D_LMT & & & & & $0.035($ InnSalInt70) & $\begin{array}{c}0.048 \text { (InnProc) } \\
0.037 \text { (InnSalInt) }\end{array}$ & 0.009 (InnSalInt70) & $0.002($ InnSalInt $)$ \\
\hline$R \_M H T$ & & & & & & $\begin{array}{c}0.000(\text { InnProc }) \\
0.000 \text { (InnSalInt70) } \\
0.005 \text { (InnSalInt80) } \\
0.010 \text { (InnSalInt90) }\end{array}$ & & $\begin{array}{c}0.004(\text { InnSalInt }) \\
0.005 \text { (InnSalInt } 90)\end{array}$ \\
\hline D_MHT & & & & & & & $\begin{array}{c}0.002(\text { InnProd }) \\
0.001 \text { (InnSalInt } 70) \\
0.016(\text { InnSalInt } 80)\end{array}$ & \\
\hline$R \_H T$ & & & & & & & & $\begin{array}{c}0.006 \text { (PatInt } 98) \\
0.010 \text { (InnProd }) \\
0.049 \text { (InnSalInt) } \\
0.005 \text { (InnSalInt70) } \\
0.049 \text { (InnSalInt80) }\end{array}$ \\
\hline D_HT & & & & & & & & \\
\hline
\end{tabular}

$p$-value from a test of equality of estimated coefficients of $R$ intensity and D intensity (by the firm's industry following the OECE classification). Only $\mathrm{p}$-values $<0.05$ are shown.

Relevant equation in parentheses: Pat (probit model for patent application); PatInt (OLS for patent intensity); PatInt\# (quantile regression for patent intensity; 90th, 94th and 98th percentiles); InnProd (probit model for product innovation); InnProc (probit model for process innovation); InnSalInt (OLS for innovative sales intensity); InnSalInt\# (quantile regression for innovative sales intensity; 70th, 
Table A8. The differentiated effect of Research and Development on patent application

Industry interactions: Pavitt taxonomy

\begin{tabular}{|c|c|c|c|c|c|c|c|c|c|c|}
\hline \multirow[b]{4}{*}{$R$ intensity-sd } & \multirow{2}{*}{\multicolumn{2}{|c|}{$\begin{array}{c}\text { (a) } \\
\text { Probability of } \\
\text { patent } \\
\text { application }\end{array}$}} & \multicolumn{2}{|c|}{ (b) } & \multicolumn{2}{|c|}{ (c) } & \multicolumn{2}{|c|}{ (d) } & \multicolumn{2}{|r|}{ (e) } \\
\hline & & & \multicolumn{6}{|c|}{$\begin{array}{l}\text { Number of patent applications } \\
\text { (Patent application intensity) }\end{array}$} & & \\
\hline & \multicolumn{2}{|c|}{ Probit } & \multicolumn{2}{|c|}{ OLS } & \multicolumn{2}{|c|}{$\begin{array}{l}\text { Quantile regression } \\
\left(90^{\text {th }} \text { percentile }\right)\end{array}$} & \multicolumn{2}{|c|}{$\begin{array}{l}\text { Quantile regression } \\
\left(94^{\text {th }} \text { percentile }\right)\end{array}$} & \multicolumn{2}{|c|}{$\begin{array}{l}\text { Quantile regression } \\
\left(98^{\text {th }} \text { percentile }\right)\end{array}$} \\
\hline & $0.011^{* *}$ & $(0.004)$ & 0.030 & $(0.034)$ & $0.402^{* * * * *}$ & $(0.097)$ & $0.159^{*}$ & $(0.074)$ & 0.128 & $(0.065)$ \\
\hline$R$ intensity-si & $0.008_{* * *}^{*}$ & $(0.003)$ & 0.044 & $(0.025)$ & $0.339^{* * * *}$ & $(0.074)$ & 0.115 & $(0.062)$ & 0.089 & $(0.057)$ \\
\hline$R$ intensity-ss & $0.015^{* * *}$ & $(0.003)$ & 0.003 & $(0.018)$ & $0.226^{* *}$ & $(0.080)$ & 0.060 & $(0.062)$ & 0.089 & $(0.054)$ \\
\hline$R$ intensity-sb & $0.016^{* *}$ & $(0.005)$ & 0.014 & $(0.035)$ & $0.459^{* * *}$ & $(0.113)$ & $0.175^{*}$ & $(0.089)$ & $0.151^{*}$ & $(0.069)$ \\
\hline$D$ intensity-sd & $0.014^{* *}$ & $(0.005)$ & 0.013 & $(0.030)$ & $0.646^{* * *}$ & $(0.119)$ & 0.170 & $(0.090)$ & 0.131 & $(0.084)$ \\
\hline$D$ intensity-si & $0.010^{*}$ & $(0.004)$ & 0.029 & $(0.032)$ & $0.463^{* * *}$ & $(0.085)$ & $0.177^{*}$ & $(0.071)$ & 0.070 & $(0.065)$ \\
\hline$D$ intensity-ss & $0.012^{* *}$ & $(0.005)$ & 0.009 & $(0.032)$ & 0.165 & $(0.118)$ & 0.094 & $(0.093)$ & -0.020 & $(0.082)$ \\
\hline$D$ intensity-sb & $0.009^{*}$ & $(0.004)$ & 0.017 & $(0.031)$ & 0.115 & $(0.103)$ & 0.093 & $(0.073)$ & $0.168^{* *}$ & $(0.057)$ \\
\hline Size & $0.022^{*-x}$ & $(0.004)$ & $-0.537^{* 6 \mathrm{k}}$ & $(0.029)$ & -0.027 & $(0.080)$ & -0.296 & $(0.067)$ & $-0.431^{\text {san }}$ & $(0.062)$ \\
\hline External $R \& D$ intensity & $0.012^{* * *}$ & $(0.002)$ & 0.020 & $(0.013)$ & $0.273^{\text {*** }}$ & $(0.045)$ & $0.120^{\text {*a* }}$ & $(0.034)$ & $0.090^{* *}$ & $(0.031)$ \\
\hline Cooperation & $0.034^{* *}$ & $(0.012)$ & -0.156 & $(0.088)$ & $0.619^{*}$ & $(0.301)$ & 0.048 & $(0.228)$ & 0.141 & $(0.207)$ \\
\hline Information factors & 0.008 & $(0.027)$ & 0.088 & $(0.196)$ & -0.064 & $(0.658)$ & -0.275 & $(0.504)$ & 0.043 & $(0.491)$ \\
\hline Cost factors & -0.004 & $(0.022)$ & -0.252 & $(0.160)$ & 0.347 & $(0.531)$ & 0.322 & $(0.412)$ & -0.477 & $(0.379)$ \\
\hline Spillovers & $0.111^{* * *}$ & $(0.021)$ & 0.054 & $(0.189)$ & $2.448^{\text {*** }}$ & $(0.505)$ & $1.229^{* *}$ & $(0.393)$ & 0.532 & $(0.360)$ \\
\hline Scale-Intensive industry & 0.011 & $(0.057)$ & -0.313 & $(0.404)$ & 0.074 & $(1.219)$ & -0.437 & $(0.924)$ & 0.192 & $(0.868)$ \\
\hline Specialized-Suppliers industry & 0.057 & $(0.069)$ & 0.150 & $(0.414)$ & $5.129^{* * *}$ & $(1.404)$ & 1.359 & $(1.055)$ & 1.534 & $(0.986)$ \\
\hline Science-based industry & -0.028 & $(0.061)$ & 0.021 & $(0.489)$ & 1.008 & $(1.474)$ & -0.453 & $(1.085)$ & -0.644 & $(0.937)$ \\
\hline Number of firms & \multicolumn{2}{|c|}{4,024} & \multirow{2}{*}{\multicolumn{2}{|c|}{$\begin{array}{c}647 \\
0.487\end{array}$}} & \multicolumn{2}{|c|}{4,024} & \multicolumn{2}{|c|}{4,024} & \multicolumn{2}{|r|}{4,024} \\
\hline R-squared & & & & & & & & & & \\
\hline Log-Likelihood & \multicolumn{2}{|c|}{$-1,612.489$} & & & \multirow{2}{*}{\multicolumn{2}{|c|}{0.095}} & \multirow{2}{*}{\multicolumn{2}{|c|}{0.059}} & \multirow{2}{*}{\multicolumn{2}{|c|}{0.067}} \\
\hline $\begin{array}{l}\text { Pseudo R-squared } \\
\text { Test } \rho=0^{1}\end{array}$ & \multicolumn{2}{|c|}{0.091} & & & & & & & & \\
\hline
\end{tabular}


Table A9. The differentiated effect of Research and Development on technological innovation

Industry interactions: Pavitt taxonomy

\begin{tabular}{|c|c|c|c|c|c|c|c|c|}
\hline & \multirow{2}{*}{\multicolumn{2}{|c|}{$\begin{array}{c}\text { (a) } \\
\text { Product } \\
\text { innovation }\end{array}$}} & \multirow{2}{*}{\multicolumn{2}{|c|}{$\begin{array}{c}\text { (b) } \\
\text { Process } \\
\text { innovation }\end{array}$}} & \multicolumn{4}{|c|}{ (c) } \\
\hline & & & & & $\begin{array}{l}\text { Proc } \\
\text { innov }\end{array}$ & $\begin{array}{l}\text { uct } \\
\text { ation }\end{array}$ & $\begin{array}{l}\text { Proc } \\
\text { innov }\end{array}$ & $\begin{array}{l}\text { ess } \\
\text { ation }\end{array}$ \\
\hline & \multicolumn{2}{|c|}{ Probit } & \multicolumn{2}{|c|}{ Probit } & \multicolumn{4}{|c|}{ Bivariate Probit } \\
\hline$R$ intensity-sd & $0.012^{*}$ & $(0.006)$ & $0.016^{* *}$ & $(0.005)$ & $0.012^{*}$ & $(0.006)$ & $0.016^{* *}$ & $(0.005)$ \\
\hline$R$ intensity-si & $0.024^{* * *}$ & $(0.004)$ & $0.013^{* *}$ & $(0.004)$ & $0.024^{* * *}$ & $(0.004)$ & $0.013^{* *}$ & $(0.004)$ \\
\hline$R$ intensity-ss & $0.019^{* * *}$ & $(0.005)$ & $0.016^{* * *}$ & $(0.004)$ & $0.019^{* * *}$ & $(0.005)$ & $0.016^{* * *}$ & $(0.004)$ \\
\hline$R$ intensity-sb & $0.013^{*}$ & $(0.006)$ & 0.009 & $(0.006)$ & $0.013^{*}$ & $(0.006)$ & 0.009 & $(0.006)$ \\
\hline$D$ intensity-sd & $0.015^{*}$ & $(0.007)$ & $0.014^{*}$ & $(0.006)$ & $0.016^{*}$ & $(0.007)$ & $0.014^{*}$ & $(0.006)$ \\
\hline$D$ intensity-si & $0.028^{* * *}$ & $(0.005)$ & $0.022^{* * *}$ & $(0.005)$ & $0.028^{* * *}$ & $(0.005)$ & $0.022^{* * *}$ & $(0.005)$ \\
\hline$D$ intensity-ss & $0.035^{* * *}$ & $(0.007)$ & 0.003 & $(0.006)$ & $0.035^{* * *}$ & $(0.007)$ & 0.003 & $(0.006)$ \\
\hline$D$ intensity-sb & $0.025^{* * *}$ & $(0.006)$ & -0.001 & $(0.006)$ & $0.025^{* * * *}$ & $(0.006)$ & -0.001 & $(0.006)$ \\
\hline Size & $0.034^{* * *}$ & $(0.005)$ & $0.047^{* * *}$ & $(0.005)$ & $0.034^{* * *}$ & $(0.005)$ & $0.047^{* * *}$ & $(0.005)$ \\
\hline External $R \& D$ intensity & $0.009^{* * *}$ & $(0.003)$ & 0.004 & $(0.002)$ & $0.009^{\text {*** }}$ & $(0.003)$ & 0.004 & $(0.002)$ \\
\hline Cooperation & $0.078^{* * *}$ & $(0.018)$ & $0.053^{* * *}$ & $(0.016)$ & $0.078^{* * *}$ & $(0.018)$ & $0.053^{* *}$ & $(0.016)$ \\
\hline Information factors & -0.005 & $(0.038)$ & 0.037 & $(0.035)$ & -0.005 & $(0.038)$ & 0.037 & $(0.035)$ \\
\hline Cost factors & -0.043 & $(0.031)$ & 0.021 & $(0.029)$ & -0.043 & $(0.031)$ & 0.021 & $(0.029)$ \\
\hline Spillovers & $0.128^{* * *}$ & $(0.031)$ & $0.081^{* *}$ & $(0.029)$ & $0.128^{* * *}$ & $(0.031)$ & $0.081^{* *}$ & $(0.029)$ \\
\hline Scale-Intensive industry & $-0.171^{*}$ & $(0.068)$ & 0.005 & $(0.063)$ & $-0.168^{*}$ & $(0.068)$ & 0.002 & $(0.064)$ \\
\hline Specialized-Suppliers industry & -0.085 & $(0.080)$ & -0.028 & $(0.073)$ & -0.082 & $(0.081)$ & -0.030 & $(0.074)$ \\
\hline Science-based industry & -0.045 & $(0.083)$ & 0.078 & $(0.069)$ & -0.041 & $(0.083)$ & 0.076 & $(0.069)$ \\
\hline Number of firms & \multicolumn{2}{|c|}{4,024} & \multicolumn{2}{|c|}{4,024} & \multicolumn{4}{|c|}{4,024} \\
\hline Log-Likelihood & \multicolumn{2}{|c|}{$-2,604.788$} & \multicolumn{2}{|c|}{$-2,340.761$} & \multicolumn{4}{|c|}{$-4,917.134$} \\
\hline Pseudo R-squared & \multicolumn{2}{|c|}{0.056} & \multicolumn{2}{|c|}{0.055} & & & & \\
\hline
\end{tabular}

Robust standard errors in parentheses. ***significant at $1 \%$, ** significant at $5 \%$, *significant at $10 \%$.

Coefficients are the marginal effect of the independent variable. 
Table A10. The differentiated effect of Research and Development on innovative sales Industry interactions: Pavitt taxonomy

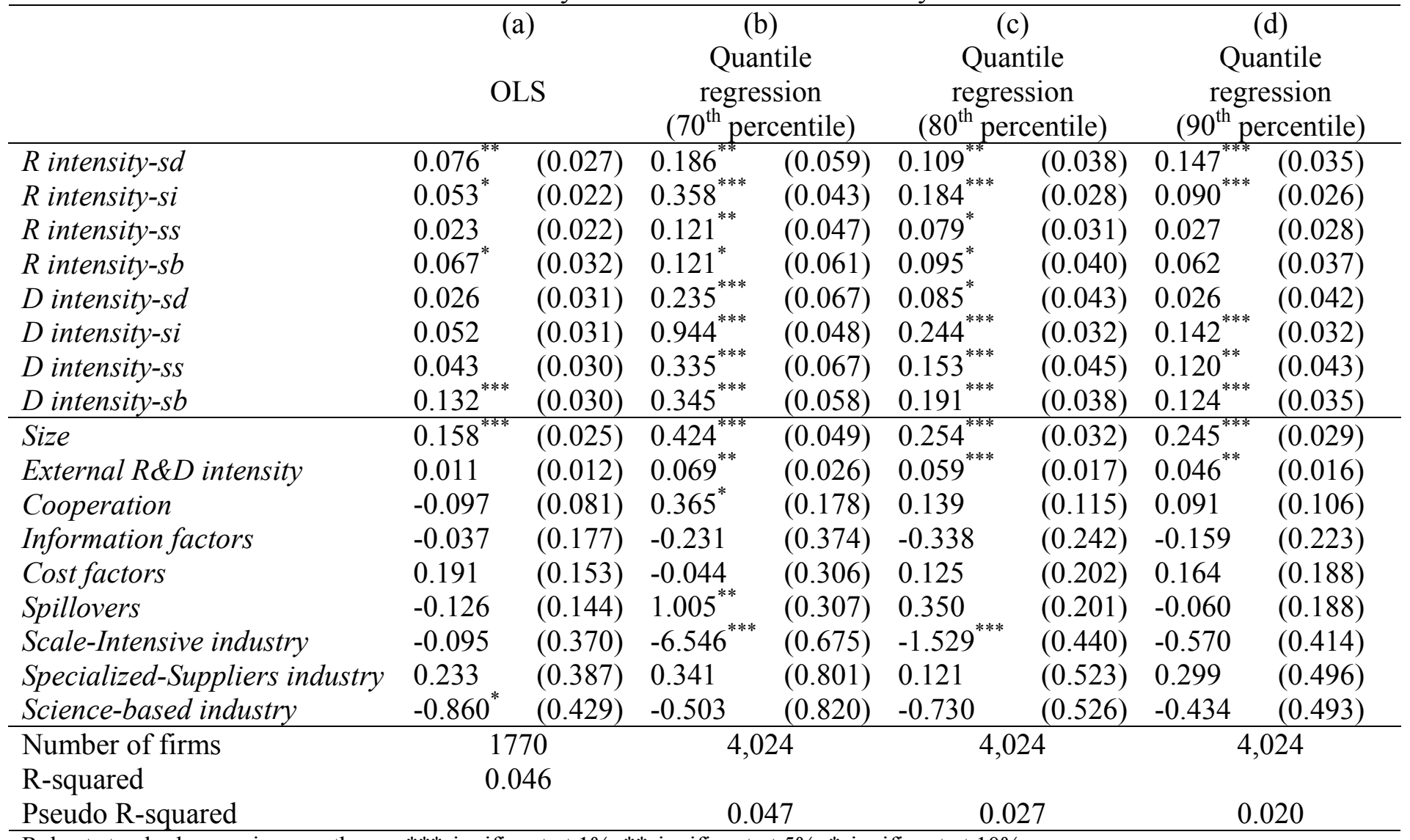

Robust standard errors in parentheses. $* * *$ significant at $1 \%, * *$ significant at $5 \%$, *significant at $10 \%$. 